TITLE:

\title{
Unified analysis of kinematic and inertial earthquake pile responses via the single-input response spectrum method
}

\section{$\operatorname{AUTHOR}(\mathrm{S}):$}

Kojima, K.; Fujita, K.; Takewaki, I.

\section{CITATION:}

Kojima, K.... [et al]. Unified analysis of kinematic and inertial earthquake pile responses via the single-input response spectrum method. Soil Dynamics and Earthquake Engineering 2014, 63: 36-55

ISSUE DATE:

2014-08

URL:

http://hdl.handle.net/2433/187051

\section{RIGHT:}

@ 2014 Elsevier Ltd.; この論文は出版社版でありません。引用の際には 出版社版をご確認ご利用ください。; This is not the published version. Please cite only the published version. 


\title{
Unified Analysis of Kinematic and Inertial Earthquake Pile Responses via Single-input Response Spectrum Method
}

\author{
K. Kojima, K. Fujita and I. Takewaki * \\ Dept. of Architecture \& Architectural Eng., Graduate School of Eng., Kyoto University, \\ Kyotodaigaku-Katsura, Nishikyo, Kyoto 615-8540, Japan
}

\begin{abstract}
In the seismic response of a structure-pile-soil system, a kinematic response due to the forced displacement of the surface ground is important, especially in a soft ground, together with the inertial response due to the inertial forces from superstructures. In this paper it is shown that a response spectrum method in terms of complex modal quantities can be used in the evaluation of the maximum kinematic and inertial seismic responses of the structure-pilesoil system to the ground motion defined at the engineering bedrock surface as an acceleration response spectrum. The notable point is that the kinematic response, the inertial response and the total response can be evaluated by the same analysis model and method by changing the model parameters. Then it is discussed which of the simple sum or the SRSS of the kinematic and inertial responses is appropriate even in resonant cases for the evaluation of the maximum pile-head bending moment. It is concluded through many examples that the validity of the simple sum or the SRSS depends on the relation between the fundamental natural period of the surface ground and that of the superstructure while an averaged evaluation is valid in resonant cases.
\end{abstract}

Keywords: Response spectrum method, Structure-pile-soil system, Complex modal combination, Kinematic effect, Inertial effect, Superposition rule, Bedrock input

\footnotetext{
* Corresponding author. Tel.: +81-75-383-3294, Fax: +81-75-383-3297, E-mail: takewaki@archi.kyoto-u.ac.jp
} 


\section{Introduction}

\subsection{Conventional method for estimating seismic pile response}

For the pile design under earthquake loading, the method for predicting the pile response is important. In the evaluation of the bending moment in a pile, both the effect of the forced displacement of a free-field ground (action 1) and the effect of the inertial force from a superstructure (action 2) as shown in Fig.1 have to be taken into account in an appropriate manner (for example [1-11]). However these two effects have different characteristics and it seems difficult to include these in a simple way keeping a reasonable accuracy. Conventionally the following two methods have been used in practice.

\subsubsection{Direct method}

The most well-known method is the direct method. This method uses a complete structure-pile-soil system in which the soil resistance around a pile is modeled by a spring or a finite element system. The spring model is known to be practical once its accuracy is confirmed by the comparison with other methods (a finite element system, a continuum model or physical experiment). The earthquake ground motion is input into the engineering bedrock. Although the finite element method has much flexibility, it has the following issues to be resolved when used in the practical design.

(1) Three-dimensional analysis of soil and pile elements requires huge computational load and resources.

(2) Deformation compatibility between soil and pile elements is difficult to satisfy and requires a constraint on the selection of finite elements [12]. For example the program 'FLUSH' [13] uses a linear displacement in soil elements and a cubic displacement in pile elements which result in the deformation incompatibility.

\subsubsection{Substructure method}

Another well-known and practical method is the substructure method (see Fig.2). The free-field ground motion is computed first to the engineering bedrock input and that is reinput to the structure-pile system. This method is aimed at superposing simply the response 
(kinematic response) due to the forced displacement of the free-field ground and the response (inertial response) due to the inertial force from a superstructure. There are two methods in the substructure method, i.e. the static method and the dynamic method. In the static method, the forced displacement of the free-field ground and the inertial force from the superstructure are given statically. Although the static method is a simple practical method, it has the following drawbacks.

(1) Difficulty in estimating the displacement mode of the free-field ground: The displacement mode is based on the lowest mode in general and higher-mode effects are missing. In addition, the amplitude of the displacement mode has to be evaluated independently.

(2) Difficulty in estimating the inertial force to be applied to piles: The estimation of exact inertial forces is possible through a versatile model. Although a sway-rocking model is often used, the input motion has to be evaluated as one including the surface soil amplification. This modeling of surface soil amplification and the specification of the response spectrum at the ground surface are cumbersome tasks.

(3) Uncertainty in superposing the above-mentioned kinematic and inertial responses: The simple sum is usually employed. However there is no guarantee depending on the relation of the fundamental natural period of the surface ground and that of the building.

\subsection{Significance of response spectrum method in hybrid problems of structural and geotechnical engineering}

After the past major earthquakes, it has been pointed out and demonstrated repeatedly that the damage to civil engineering structures is influenced greatly by the natures and conditions of surface soils and deep understanding of the soil-foundation interaction is extremely important for the mitigation of such damage. On the other hand, the soil conditions are different site by site and the definition of appropriate design ground motions at a specific site is very difficult. In the actual structural design using the structure-foundation-soil interaction models, a computationally efficient method with a reasonable accuracy is preferred from the economical and practical viewpoints. It is therefore strongly desired to develop an efficient evaluation method of the peak seismic responses of structure-foundation- 
soil systems at a specific site with a reasonable accuracy.

Compared to building structures, the application of the response spectrum methods to geotechnical problems seems to be inactive. This is because the phenomena in the geotechnical engineering are mostly described by the wave propagation theories and the treatment of those phenomena as vibration problems has seldom been conducted so far except models with viscous or transmitting boundaries [10]. While the wave propagation theories can deal with an infinite medium and hysteretic damping, a complex treatment is necessary in the vibration theories. This difficulty seems to have been the principal barrier to the introduction of the response spectrum method in geotechnical problems or structural and geotechnical engineering hybrid problems.

In this paper, a pile-soil system is considered as a representative model of the foundation-soil systems. In the evaluation of the seismic response of the pile-soil system, a kinematic effect due to the forced displacement of a free-field surface ground is important, especially in a soft ground, together with the inertial effect due to the inertial forces from superstructures (see Fig.3). A response spectrum method using complex modal combination is utilized for the simple evaluation of the maximum seismic response of the pile-soil system to the ground motion defined at the engineering bedrock surface as an acceleration response spectrum. The superposing rule of the pile bending moments due to the kinematic and inertial effects will be discussed in detail even in resonant cases.

\subsection{Recent development of response spectrum methods}

In Japan, the method based on time-history response analysis is the method well accepted in the evaluation of the seismic safety of high-rise buildings and base-isolated buildings. This is because the modal combination rules, e.g. the SRSS [14], the CQC [15], the absolute sum, are based on some assumptions; (1) the design response spectrum is prepared as the representative of the design ground motions, (2) only the elastic response can be dealt with, (3) the proportional damping can be assumed in the structures. However, in Japan, several recorded or simulated ground motions are used as the input motions in the time-history response analysis in the evaluation of the seismic safety of high-rise buildings 
and the base-isolated buildings and the design response spectrum is not a unique form of the design ground motions. For example, it is well-known [16, 17] that long-period ground motions are well represented by the energy spectrum than the ordinary response spectrum. In some buildings, nonlinear inelastic responses are allowed and these responses are difficult to deal with by the modal superposition rules. Furthermore, the proportional damping can not be assumed in most of these building structures.

In 2000 after the Hyogoken-Nanbu earthquake (Kobe earthquake), dual level acceleration response spectra were introduced at the engineering bedrock surface for the seismic safety and functionality of low and medium-rise buildings lower than $60 \mathrm{~m}$ in the new Japanese seismic-resistant design code (Standard Building Law in Japan). Those dual level acceleration response spectra for damping ratio=0.05 are shown in Fig.4.

\subsection{Treatment of design response spectrum at engineering bedrock}

Because the acceleration response spectra are defined at the engineering bedrock surface, some difficult problems arise. There are three approaches to these acceleration response spectra at the engineering bedrock surface (see Fig.5). One is the transformation of the acceleration response spectra at the engineering bedrock surface into those at the ground surface or at the bottom of a buried foundation (Fig.5(a)) and another one is the introduction of an overall interaction system (Fig.5(b)). The other one is the introduction of substructure models subjected to multiple inputs (Fig.5(c)).

As for the transformation of the acceleration response spectra at the engineering bedrock surface into those at the ground surface or at the bottom of a buried foundation, the approximate amplification factors are prepared depending on the surface ground conditions. The surface ground may be modeled based on the one-dimensional wave propagation theory [18] and a more detailed amplification factor can be used as a result. However, recorded or simulated ground motions have to be defined at the engineering bedrock surface and the amplification factors can be affected greatly by the properties of ground motions.

Another approach using an overall interaction system is based on the model of a single input at the engineering bedrock. This approach can be incorporated into the conventional 
response spectrum method developed for a single input. However, a numerical stability problem may arise in this overall model due to the much difference in numerical order between the free-field ground and the pile-soil system. The method developed in [10] is applied to the problem for investigating the superposition rule of the kinematic and inertial responses of the structure-pile-soil system.

The other approach using substructure models subjected to multiple inputs has a difficulty in applying the conventional response spectrum method because the conventional response spectrum method can not usually deal with the multiple inputs. However this approach is useful for the accuracy confirmation of the method used in this paper.

The relation between the inertial response and the kinematic response in the evaluation of the maximum pile-head bending moment has been investigated by Murono and Nishimura [6], Tokimatsu et al. [8, 9]. However the proposal of more comprehensive analysis methods is desired and this can be done efficiently and effectively by combining the response spectrum method proposed in [10] with a new method for evaluating the inertial response. A simple analysis method of the inertial response using the same response spectrum method is proposed here by introducing the constraint on the free-field ground (the fixed condition of the free-field ground) and an amplification factor for the total inertial response (Section 4).

\subsection{Novelties}

The highlights of this paper may be summarized as follows:

(1) The introduction of the response spectrum method in the complicated soil-pile-structure model enabled the detailed analysis of the accuracy in the combination rule of kinematic and inertial effects,

(2) The combination rule was not clear in the range of resonance between the natural period of the superstructure and that of the ground in the previous research,

(3) The proposal of the method for evaluating the dynamic inertial effect without the time history response analysis using the total system (Section 2 and Section 4),

(4) The use of the overall system with a single input instead of the multi-input model enabled the application of the simple response spectrum method, 
(5) The simultaneous analysis of kinematic and inertial effects by the unified response spectrum method (unified analysis model and method: the previous research is an analysis of experimental data (not the proposal of response analysis methods)).

\section{Kinematic and Inertial Responses in Structure-pile-soil System under Earthquake}

\section{Loading}

It is well-known that the earthquake response of a structure-pile-soil system can be described in terms of the kinematic and inertial responses as stated before. Since it seems beneficial to explain its essence for the development of a new theory proposed in this paper, a simple model as shown in Fig.6 is introduced first.

Let $m_{G}, m_{0}, m_{1}$ denote the masses of the free-field ground, the foundation and the superstructure. The stiffnesses of the free-field ground, the pile, the interaction soil and the superstructure are expressed by $k_{G}, k_{P}, k_{I}, k_{1}$. Assume that the displacement is expressed in terms of the inertial response $u_{0}^{(I)}$ and the kinematic response $u_{0}^{(K)}$ as

$$
u_{0}=u_{0}^{(I)}+u_{0}^{(K)}
$$

By summing up Eq.(A1a) and Eq.(A1b) in Appendix-1 and substituting Eq.(1) into the remaining equation, the following relation holds.

$$
\sum_{i=0}^{1} m_{i}\left(\ddot{u}_{g}+\ddot{u}_{i}\right)+k_{I}\left(u_{0}^{(I)}+u_{0}^{(K)}-u_{G}\right)+k_{P}\left(u_{0}^{(I)}+u_{0}^{(K)}\right)=0
$$

From the definitions of $u_{0}^{(I)}$ and $u_{0}^{(K)}$, the following two equations as the constituents of Eq.(2) are derived.

$$
\begin{aligned}
& \sum_{i=0}^{1} m_{i}\left(\ddot{u}_{g}+\ddot{u}_{i}\right)+k_{I} u_{0}^{(I)}+k_{P} u_{0}^{(I)}=0 \\
& k_{I}\left(u_{0}^{(K)}-u_{G}\right)+k_{P} u_{0}^{(K)}=0
\end{aligned}
$$

Eq.(3a) indicates that the total response $u_{0}$ and $u_{1}$ are necessary to obtain $u_{0}^{(I)}$. Furthermore $u_{0}^{(I)}$ can be obtained for the structure-pile system under the total inertial forces 
$\sum_{i=0}^{1} m_{i}\left(\ddot{u}_{g}+\ddot{u}_{i}\right)$ without $u_{G}$. It should be noted that the following relation holds in comparison with Eq.(3a).

$$
\sum_{i=0}^{1} m_{i}\left(\ddot{u}_{g}+\ddot{u}_{i}^{(R)}\right)+k_{I} u_{0}^{(R)}+k_{P} u_{0}^{(R)}=0
$$

$u_{0}^{(R)}$ and $u_{1}^{(R)}$ in Eq.(4) denote the responses of masses $m_{0}$ and $m_{1}$ of the structure-pile model with the rigid free-field ground under $\ddot{u}_{g}$. The maximum value of the first term of Eq.(4) indicates $Q^{(R)}$ and this value can be computed from the response of the model with the rigid free-field ground under $\ddot{u}_{g}$. The analysis of the relation between Eq.(3a) and Eq.(4) seems useful for the development of a new evaluation method for the inertial response of piles (see Section 4). On the other hand, Eq.(3b) implies that $u_{0}^{(K)}$ can be computed for the massless superstructure model under the input $u_{G}$.

The explanation in this section is for providing the fundamental concept for decomposing the total response into kinematic and inertial parts. In the subsequent sections, the equivalent soil stiffness evaluated in the analysis of the free-field ground is used. A more detailed analysis (multi-input model including local soil nonlinearity) is shown in Section 6.2 for comparison.

\section{Response Spectrum Method for Free-field Ground and Structure-pile-soil System}

\subsection{Ground model}

Consider an idealized ground model which consists of $\mathrm{N}-1$ homogeneous horizontal soil layers on semi-infinite homogeneous ground. This semi-infinite ground is called an engineering bedrock for structural design purposes. The design earthquake is defined at the upper surface level of the engineering bedrock as the design acceleration response spectrum for outcropping motion in accordance with the aforementioned Japanese code (see Fig.4). This upper surface level of the engineering bedrock is called later the engineering bedrock surface. The numbering of the soil layers starts from the ground surface and the engineering bedrock is the $N$-th layer. Let $u_{m}$ denote the horizontal displacement of the interface between the $(m-1)$-th soil layer and the $m$-th soil layer. The thickness of the $m$-th soil layer is 
denoted by $h_{m}$.

It is usual to employ a hysteretic damping in soil while a viscous damping is also proposed from another viewpoint [19]. Let $G_{m}, \beta_{m}, \rho_{m}$ denote the shear modulus, the hysteretic damping ratio and the mass density of the $m$-th soil layer, respectively. Dependence of shear moduli and damping ratios on the strain level is taken into account in the equivalent linear model [18].

\subsection{Response spectrum method for free-field ground}

A response spectrum method has been used primarily for structures with viscous damping because equations of motion under arbitrary loading are difficult to describe in time domain for structures with linear hysteretic damping (complex damping) due to the causality law. For this reason, the hysteretic damping is substituted by a viscous damping in this paper. Then the hysteretic damping ratio is used as the viscous damping ratio for the lowest vibration mode. The substituted ground has non-proportional damping and complex eigenvalue analysis is required for accurate analysis. For vibration analysis, a viscous boundary is introduced at the base as shown in Fig.5(b).

Let $h^{(j)}$ and $\omega^{(j)}$ denote the pseudo damping ratio and the pseudo natural frequency for the $j$-th eigenvibration. The definition of $h^{(j)}$ and $\omega^{(j)}$ is shown in Appendix-2. The mean value of the peak shear strains in the $k$-th layer may be evaluated by the response spectrum method due to Yang et al. [20].

$$
\gamma_{k \max }=\frac{1}{h_{k}} \sqrt{\sum_{i=1}^{n} \sum_{j=1}^{n}\left\{\delta_{s k}^{(i)} \rho_{s s}^{(i j)} \delta_{s k}^{(j)}+2 \delta_{s k}^{(i)} \rho_{s c}^{(i j)} \delta_{c k}^{(j)}+\delta_{c k}^{(i)} \rho_{c c}^{(i j)} \delta_{c k}^{(j)}\right\}},
$$

where $n$ denotes the number of modes to be considered and $\delta_{s k}^{(i)}, \delta_{c k}^{(i)}, \rho_{s s}^{(i j)}, \rho_{c c}^{(i j)}, \rho_{s c}^{(i j)}$ are given in Appendix-2 [20]. The effective shear strain in the $k$-th soil layer is evaluated by $\gamma_{\text {keff }}=0.65 \times \gamma_{k \max }$.

\subsection{Response spectrum method for structure-pile-soil system}

The efficient finite-element model, as shown in Fig.5(b), with the Winkler-type 
springs for the pile-soil systems has been proposed in [21-23]. The displacement function of the free-field ground is assumed to be linear and that of the pile is assumed to be cubic. In order to satisfy the deformation compatibility at both sides, the horizontal displacement in this element is required to be cubic. Viscous boundaries are incorporated at the bottom of that model and a response spectrum method similar to that for the free-field ground [24] is developed.

The Winkler-type spring is modeled as a dynamic spring [1] with frequency dependent damping coefficients. The damping ratios are the combination of the hysteretic one and the radiation one and the expression will be shown in numerical examples later. The frequencydependent damping coefficient is transformed into the frequency-independent one evaluated at the fundamental natural frequency of the superstructure. This is essential for the use of the response spectrum method. The area of the free-field ground is very important from the viewpoint of numerical stability and the appropriate expression of interaction between the pile and the free-field. In this paper, the area of the free-field ground is assumed to be $1.0 \times 10^{6}\left(\mathrm{~m}^{2}\right)$ based on the fact that the transfer function amplitude of the free-field ground surface displacement is stable over the area of $1.0 \times 10^{5}\left(\mathrm{~m}^{2}\right)$ [10].

Once a complex eigenvalue analysis is performed, the procedure of application of the response spectrum method explained in the foregoing section to this model can be developed straightforwardly.

The element stiffness matrix for the interaction springs can be found in [21, 22]. The corresponding element damping matrix for the interaction dashpots has been taken into account. The consistent masses of the free-field ground and the pile have been considered.

The mean value of the maximum bending moment and shear force at the pile head may be evaluated by

$$
\begin{aligned}
& M_{\max }=\sqrt{\sum_{i=1}^{n} \sum_{j=1}^{n}\left\{Z_{s}^{(i)} \rho_{s s}^{(i j)} Z_{s}^{(j)}+2 Z_{s}^{(i)} \rho_{s c}^{(i j)} Z_{c}^{(j)}+Z_{c}^{(i)} \rho_{c c}^{(i j)} Z_{c}^{(j)}\right\}} \\
& Q_{\max }=\sqrt{\sum_{i=1}^{n} \sum_{j=1}^{n}\left\{Y_{s}^{(i)} \rho_{s s}^{(i j)} Y_{s}^{(j)}+2 Y_{s}^{(i)} \rho_{s c}^{(i j)} Y_{c}^{(j)}+Y_{c}^{(i)} \rho_{c c}^{(i j)} Y_{c}^{(j)}\right\}}
\end{aligned}
$$


where

$$
\begin{aligned}
& Z_{s}^{(i)}=E I \times S_{D s}^{(i)} \operatorname{Re}\left[v^{(i)} \kappa^{(i)}\right], Z_{c}^{(i)}=E I \times S_{D c}^{(i)} \operatorname{Re}\left[v^{(i)} \kappa^{(i)}\right] \\
& Y_{s}^{(i)}=E I \times S_{D s}^{(i)} \operatorname{Re}\left[v^{(i)} \zeta^{(i)}\right], Y_{c}^{(i)}=E I \times S_{D c}^{(i)} \operatorname{Re}\left[v^{(i)} \zeta^{(i)}\right]
\end{aligned}
$$

In Eqs.(8) and (9), EI is the bending stiffness of the pile and $\kappa^{(i)}$ is the curvature component at the pile head in the $i$-th complex eigenmode. $\zeta^{(i)}$ is the derivative of the curvature component with respect to the pile axial coordinate at the pile head in the $i$-th complex eigenmode.

In order to investigate the accuracy of the present method using the dynamic Winklertype spring, a single pile of diameter $=1.0(\mathrm{~m})$ and length $=20(\mathrm{~m})$ in a homogeneous semiinfinite ground of shear wave velocity $=100(\mathrm{~m} / \mathrm{s})$ and damping ratio=0.05 has been analyzed in [10]. It has been demonstrated through the comparison with the thin-layer method [25-27] that the present method using the dynamic Winkler-type spring has a reasonable accuracy.

In addition, for investigating the accuracy of the present method, the comparison with the continuum model [23] has been made. A two-story shear building model on a surface ground of two soil layers (depth of each soil layer=10(m), shear wave velocity $=100(\mathrm{~m} / \mathrm{s}$ ), 200(m/s) from the top, pile diameter=1.5(m)) has been analyzed in [10]. It has been disclosed that a fairly good correspondence can be seen in the case of using the Rayleigh damping and this supports clearly the validity of the present FEM model.

\subsection{Extraction of kinematic response}

The kinematic response of the pile-head bending moment due to the forced displacement of the free-field ground under no inertial force from the super-structure can be evaluated by specifying the zero masses in the super-structure and foundation as explained in Section 2 (see Fig.3). The same analysis model except these zero masses and the same analysis method (response spectrum method) can be used.

\section{Evaluation of Inertial Response}


The inertial response can be evaluated conventionally by the pile-head shear force $Q^{\text {total }}$ from the total response and the static response under this pile-head shear force at the rest of the free-field ground (no deformation of free-field ground). Although the static response is one possibility (see Fig.2) and may cause difficulties stated in Section 1.1.2, another method can be devised. If the same response spectrum method used for the total response and the kinematic response is available, it may be desirable.

Let $Q^{\text {rigid }}$ and $M^{\text {rigid }}$ denote the maximum dynamic pile-head shear force and bending moment of the model with the rigid free-field ground under a response spectrum at the engineering bedrock. It is assumed here that the shear force and bending moment distributions of a pile in an inertial response are proportional to those of the model with the rigid free-field ground under a response spectrum at the engineering bedrock. This is because, (1) the boundary condition are the same between the inertial response case (a static shear force at the pile head for a rigid free-field ground) and the model with the rigid freefield ground under a response spectrum at the engineering bedrock, (2) the pile inertial force effect is negligible in the model with the rigid free-field ground under a response spectrum at the engineering bedrock and (3) the pile bending moment in the inertial response is concentrated to the narrow range near the pile head. This issue has also been discussed in Section 2. Since $Q^{(K)} \cong 0$ and $Q^{\text {total }} \cong Q^{(I)}$, the inertial response (see Fig.3) of the pile-head bending moment may be evaluated by

$$
M^{(I)}=M^{\text {rigid }}\left(Q^{\text {total }} / Q^{\text {rigid }}\right)
$$

This relation has been validated from the fact that the sum of the super-structure inertial forces in the total response is approximately equal to the inertial one $\left(Q^{\text {total }} \cong Q^{(I)}\right)$ and that the shear force and bending moment distributions of a pile in an inertial response are proportional to those of the model with the rigid free-field ground under a response spectrum at the engineering bedrock due to the above-mentioned reasons.

\section{Numerical Examples}

\subsection{Design earthquakes at engineering bedrock surface}


The design earthquake ground motion mentioned in Section 1.3 is employed here. In the seismic-resistant design code, elastic design is required for the damage-limit level motion (the maximum spectral acceleration for damping ratio 0.05 defined for the engineering bedrock surface motion as outcropping motion is $\left.1.6\left(\mathrm{~m} / \mathrm{s}^{2}\right)\right)$ and inelastic design is allowed for the safety-limit level motion (the maximum spectral acceleration for damping ratio 0.05 is $8\left(\mathrm{~m} / \mathrm{s}^{2}\right)$ ). The design acceleration response spectrum $S_{A}$ (in $\mathrm{m} / \mathrm{s}^{2}$ for damping ratio 0.05 ) in terms of natural period $T$ for the damage-limit level motion may be expressed as

$$
\begin{aligned}
& S_{A}=0.64+6.0 T \quad(T<0.16 s) \\
& S_{A}=1.6 \quad(0.16 s \leq T \leq 0.64 s) \\
& S_{A}=1.024 / T \quad(0.64 s<T)
\end{aligned}
$$

The design acceleration response spectrum for the safety-limit level motion can be expressed by multiplying Eq.(11) by five. This design acceleration response spectrum $S_{A}$ for the damage-limit level motion and that for the safety-limit level motion are shown in Fig.4. This spectrum has a tendency similar to the conventional one [28], i.e. the constant acceleration region and the constant velocity region exist. As the amplification factors from the maximum acceleration and velocity of the input in terms of damping ratios, those (median type) proposed in [28] are used.

\subsection{Two ground models: soft and stiff ground models}

Two surface ground models, referred to as ground model A (rather soft ground) and ground model B (slightly stiff ground), are considered. The soil profiles of these two ground models are shown in Fig.7. The SPT values in the soil layers for ground models A and B are also shown for reference. The mass density of surface soil layers is assumed to be $1.8 \times 10^{3}\left(\mathrm{~kg} / \mathrm{m}^{3}\right)$ and Poisson's ratio is 0.45 . The ground model A consists of six soil layers on the engineering bedrock (the mass density is assumed to be $2.0 \times 10^{3}\left(\mathrm{~kg} / \mathrm{m}^{3}\right)$ ) and the ground model B consists of two soil layers on the engineering bedrock. In both ground models, each soil layer has been divided into sub-layers of thickness of $1(\mathrm{~m})$. As a result, the ground model A consists of 38 sub-layers and the ground model B consists of 30 sub-layers. 
To evaluate the strain-dependent nonlinearity of the ground, an equivalent linearization method [24] has been used. The strain-dependent nonlinear relations are shown in Fig.8 for clay and sand which are taken from the new Japanese seismic-resistant design code revised in June 2000. The effective strain equal to $0.65 \times$ (the maximum strain) is assumed and several iterations are conducted for convergence. The derived stiffness reduction ratios and equivalent damping ratios by the response spectrum method [10, 24] and the SHAKE program [18] for damage-limit level motion are shown in Figs.9 and 10, respectively. The fundamental natural period $T_{G}\left(=2 \pi / \omega_{G}\right)$ of the ground model $\mathrm{A}$ is $1.0(\mathrm{~s})$ and that of the ground model $\mathrm{B}$ is $0.6(\mathrm{~s})$. In case of using the SHAKE program, ground-motion time histories are necessary and ten simulated ground motions have been used [10, 24].

The damping ratios derived here are substituted into the term of the hysteretic damping $\beta$ and the following radiation damping is added to those ones [1, 2].

$$
c_{x}=\frac{2 k_{x}}{\omega_{G}}\left\{\frac{\omega_{1} d \rho_{s} V_{s}}{k_{x}}\left[1+\left(\frac{V_{c}}{V_{s}}\right)^{\frac{5}{4}}\right]\left(\frac{\omega_{1} d}{V_{s}}\right)^{-\frac{1}{4}}+\beta\right\} \quad\left(\omega_{1} \geq 2 \omega_{G}\right)
$$

In Eq.(12), $c_{x}, d, \rho_{s}, V_{s}, V_{c}, k_{x}, \omega_{1}$ are the damping coefficient of the interaction dashpot, the pile diameter, the soil mass density, the soil shear velocity, the Lysmer's analogue velocity $\left(=V_{s}\right.$ here), the Winkler-type stiffness of the interaction spring (strain-dependent equivalent one), the fundamental natural circular frequency of the superstructure. The radiation damping ratio is zero in $\omega_{1} \leq \omega_{G}$ and is linear in $\omega_{G} \leq \omega_{1} \leq 2 \omega_{G}$. The final damping ratio at each soil layer is evaluated at the fundamental natural frequency of the superstructure as a frequencyindependent one. These data are used in the computation of the kinematic effect, the inertial effect and the total response. From Figs.9 and 10, it can be seen that the present response spectrum method has a reasonable accuracy compared with the SHAKE program.

The accuracy of the response spectrum method has been demonstrated by the senior author for the total model including the kinematic and inertial effects simultaneously in terms of the transfer functions [10]. A Winkler-type continuum model has been used as another model for comparison [10]. Another comparison has been made with an actual record and the 
present method has been proven to be accurate enough when taking into account the strainamplitude nonlinearity of soil deposit [23].

It has been understood that, by the use of the response spectrum method, these distributions of shear forces and bending moments in piles in the analysis of the kinematic interaction can be obtained efficiently. Although the response spectrum method has been developed in the analysis of the kinematic interaction only and the overall system including both the kinematic and inertial interactions [10], it has been extended in this paper to the case including the inertial interaction only.

\subsection{Two, six, ten, sixteen and twenty-story building models on two ground models (damage-limit level)}

Two, six, ten, sixteen and twenty-story building models on ground models A and B are considered. The floor mass of the building for a single pile is $40 \times 10^{3}(\mathrm{~kg})$ and the mass of the foundation for a single pile is $120 \times 10^{3}(\mathrm{~kg})$. All the building models have been simplified to two-mass models (floor masses are transformed into two masses). A cast-in-place reinforced concrete pile is used and its pile diameter is $1.5(\mathrm{~m})$. The Young's modulus of concrete is $2.1 \times 10^{10}\left(\mathrm{~N} / \mathrm{m}^{2}\right)$ and the concrete mass density is $2.4 \times 10^{3}\left(\mathrm{~kg} / \mathrm{m}^{3}\right)$. The fundamental natural periods $T_{B}$ of these models with a fixed base are 0.3, 0.6, 1.0, 1.6 and 2.0(s). The relation between the fundamental natural period of the ground and that of the building model is shown in Fig.11 and the constituents of damping mechanisms are also shown. The radiation damping has been included in the 2-story and 6-story models in the ground model A and in the 2-story model in the ground model B. The damage-limit level motion has been used in this section.

Fig.12 shows the maximum bending moment distribution of the pile due to the kinematic response, the inertial response and their total response. On the other hand, Fig.13 illustrates the corresponding maximum shear force distribution of the pile due to the kinematic response, the inertial response and their total response.

Fig.14(a) shows the maximum pile-head bending moment due to the kinematic effect and that due to the inertial effect for 2, 6, 10, 16 and 20-story buildings on the ground model 
A. Fig.14(b) presents those for buildings on the ground model B. Since the kinematic effect is determined from the relation between the free-field ground and the pile, the pile-head bending moment due to the kinematic effect is almost constant for each ground. The slight difference results from the existence of the radiation damping in some models (2-story and 6story models for the ground model A and 2-story model for the ground model B). On the other hand, the pile-head bending moment due to the inertial effect depends on the ground and the building model. It should be noted that, because the ground model influences the input ground motion at the ground surface level even if the input is the same at the engineering bedrock, the ground model affects the inertial forces on the building.

It can be observed from Fig.14(a) that, since the fundamental natural period $T_{B}$ (1.0s) of the 10-story building with fixed base coincides with the fundamental natural period $T_{G}$ (1.0s) of the ground model A, the pile-head bending moment due to the inertial effect of the 10-story building on the ground model A exhibits the largest value compared to other building models. A similar phenomenon can be observed in the 6-story building (fundamental natural period $=0.6 \mathrm{~s}$ ) on the ground model B (fundamental natural period $=0.6 \mathrm{~s}$ ) (see Fig.14(b)). It may be interesting to note that the inertial effect becomes smaller as the ratio of the fundamental natural period of the building to that of the ground becomes far from 1.0 even if the number of stories becomes large.

Fig.15 shows the accuracy of the simple (direct) sum and the SRSS evaluations. The simple sum and the SRSS are defined by

Simple sum $=[$ inertial response $]+[$ kinematic response $]$

SRSS $=\left([\text { inertial response }]^{2}+[\text { kinematic response }]^{2}\right)^{0.5}$

It can be observed that, at $T_{G}=T_{B}$ the true pile-head bending moment exhibits an intermediate response between the simple (direct) sum and the SRSS. On the other hand, when $T_{G}>T_{B}$, the simple sum provides a better estimation in general. In case of $T_{G}<T_{B}$, the SRSS gives a better estimation. However, when $T_{B}$ is near $T_{G}$, the proposed response spectrum method should be used. The simple sum often provides too conservative results.

For more detailed investigation, the analysis for pile diameters $1.0(\mathrm{~m})$ and $2.0(\mathrm{~m})$ has been conducted. While the case of the pile diameter $1.0(\mathrm{~m})$ for the 16-story and 20-story 
buildings and the pile diameter 2.0(m) for the 2-story and 6-story buildings may seem unrealistic, those cases are also treated for comparison. Fig.16(a) shows the maximum pilehead bending moment due to the kinematic effect and that due to the inertial effect for 2, 6, 10, 16 and 20-story buildings with the pile diameter $1.0(\mathrm{~m})$ on the ground model A. On the other hand, Fig.16(b) presents that for the ground model B. Figs.17(a) and (b) illustrate the accuracy of the simple sum and the SRSS evaluations for the pile diameter $1.0(\mathrm{~m})$. Furthermore Figs.18(a), (b) and 19(a), (b) show the corresponding figures for the pile diameter 2.0(m). It can be observed from these figures that the findings on the superposition rule of the kinematic and inertial responses obtained in the previous paragraph also apply to other cases with different pile diameters. It can also be concluded that, while larger piles make the design safer from the viewpoint of the inertial response, those do not necessarily lead to a safer design from the viewpoint of the kinematic response. It seems that there exists an optimal pile size which makes the total response minimum. This issue is open to further investigation.

\subsection{Two, six, ten, sixteen and twenty-story building models on two ground models (safety-limit level)}

Further analysis has been conducted for the building models under the safety-limit level motion at the engineering bedrock. Although the responses of superstructures and piles may often be in the plastic range under severe input motions, only elastic responses are considered here for the purpose of verifying the superposition rules even under the safetylimit level motion. The stiffness reduction ratios and equivalent damping ratios by the response spectrum method $[10,24]$ and the SHAKE program for safety-limit level motion are shown in Figs.20 and 21, respectively. The fundamental natural period $T_{G}\left(=2 \pi / \omega_{G}\right)$ of the ground model A is 1.6(s) and that of the ground model B is 1.2(s). As in the case of damagelimit level motion, ten simulated ground motions have been used in case of using the SHAKE program.

Fig.22(a) shows the maximum pile-head bending moment due to the kinematic effect and that due to the inertial effect for 2, 6, 10, 16 and 20-story buildings on the ground model 
A. Fig.22(b) presents those for buildings on the ground model B. The pile diameter is 1.5(m). It can be observed that, while the amplification of the safety-limit level motion from the damage-limit level motion is five, the response amplification is much smaller than five. This may result from the increase of damping and the nonlinear amplification effect due to change of equivalent soil stiffness.

Fig.23 shows the accuracy of the simple (direct) sum and the SRSS evaluations. It can be observed that, while the simple sum provides a better estimation in general in the case of $T_{G}>T_{B}$, the SRSS gives a better estimation in the case of $T_{G}<T_{B}$. It can also be understood that in some cases the total response is smaller slightly than the SRSS evaluation and larger slightly than the simple sum. However its difference may be negligible.

It may be concluded that the seismic response of the maximum bending moments and shear forces in piles can be evaluated efficiently and reliably by the proposed response spectrum method with an appropriate understanding of kinematic and interaction components. Furthermore the superposition method of the kinematic and inertial pile responses has been made clear for any relationship between the fundamental natural period of the super-structure and that of the ground.

The appropriateness of using the fixed-base natural period instead of the coupled model natural period should be discussed. The coupled natural period of the 2-story building model on Ground A (rather soft ground) under the damage-limit level input is 0.305 (s) and that under the safety-limit level input is 0.307(s). Therefore the effect of the coupled natural period on the combination between inertial and kinematic effects seems to be negligible.

\section{Accuracy and Reliability of Proposed Response Spectrum Method}

\subsection{Comparison with recorded data}

Since it seems meaningful to investigate the accuracy and reliability of the present response spectrum method, the comparison of the results by the present method with the recorded data [29] is provided in Appendix 3 (Figs.24, 25).

\subsection{Comparison with multi-input model including nonlinear horizontal interaction}




\section{springs}

In order to further investigate the accuracy and reliability of the present response spectrum method, a time-history analysis has been conducted and compared using the multiinput model where the interaction spring is modeled by the Hardin-Drnevich model and the Masing hysteretic rule. The analysis model is shown in Fig.26. The damping coefficients of the interaction dashpots have been evaluated based on the radiation damping component in Eq.(22). Fig.27 shows the comparison of the pile bending moments between the present response spectrum method and a multi-input model including nonlinear horizontal interaction springs placed at every pile node (every $1 \mathrm{~m}$ ). In the multi-input model, a response-spectrum compatible ground motion (damage-limit level input; Ground A; 2-story model) has been generated at the bedrock and the ground motions at different underground levels (every $1 \mathrm{~m}$ ) have been generated by using the SHAKE program. This procedure has also been repeated for the safety-limit level input (Ground A; 2-story model). It should be noted that, while the response spectrum method provides a mean peak response, the multi-input model gives one response result to one input ground motion. It can be observed that, while the present response spectrum method provides a somewhat different response distribution of pile stresses, especially for the safety-limit level input, the overall properties including the pilehead bending moment can be predicted within an acceptable accuracy.

Fig.28 shows the hysteretic responses of the soil-pile spring at the top for the damagelimit level input and the safety-limit level input.

\subsection{Earth pressure effect}

The present paper does not include the earth pressure acting on the embedded foundation. In [8, 9], the effect of the earth pressure acting on the embedded foundation is considered. The focusing point in this paper is to investigate the accuracy and reliability of the superposition method even for a simple case without the earth pressure. Especially the proposal of a unified method (same analysis model and method) for both kinematic and inertial effects is a unique point. However it seems meaningful to investigate its effect even approximately. 
The effect of earth pressure acting on an embedded foundation may be examined by modifying the stiffness of the soil-pile spring because the effect of earth pressure acting on an embedded foundation can be expressed by the additional horizontal resistance. As an example, the stiffnesses of the top three soil-pile springs in the response analysis model in Section 6.2 have been varied (100 multiples of the original values). Fig.29 shows the comparison of the maximum pile bending moments under the damage-limit level input (Ground A; 2-story model) between the original model and the modified model, simulating the earth pressure acting on an embedded foundation, for varied stiffness of three pile-soil springs near the ground surface (100 multiples of the original values). It can be observed that the increase of stiffness of top three soil-pile springs changes the maximum pile bending moment to some extent. It should be remarked that, while the increase of the soil-pile spring stiffness leads to the reduction of the pile bending moment due to the inertial effect, it leads to the increase of the pile bending moment due to the kinematic effect.

In order to investigate the change of the ratio of the inertial effect to the kinematic effect, the proposed response spectrum method has been used. Fig.30 presents the maximum bending moment distribution of the pile due to the kinematic response, the inertial response and their total response computed by the proposed response spectrum method which corresponds to the topmost one in Fig.12(a) (Ground A; 2-story building model). The stiffness of upper two interaction elements has been increased 100 times based on the equivalence with the increase of stiffness of three pile-soil springs near the ground surface employed in Fig.29 for investigating the earth pressure effect. It can be observed that, while the increase of the soil-pile spring stiffness leads to the reduction of the pile bending moment due to the inertial effect, it leads to the increase of the pile bending moment due to the kinematic effect. This property certainly guarantees the insensitive characteristic of the pile bending moment to the change of the soil-pile spring stiffness (inclusion of the earth pressure). Although it is explained in [8,9] that the embedment of a foundation usually reduces the pile stress in a non-liquefaction case, it seems that its effect depends on the model investigated. Further investigation will be necessary to include this effect in a more reliable manner. 


\subsection{Pile group effect}

Only a single pile is considered in this paper. The inclusion of the pile group effect and the effect of pile position (inner or outer: see Appendix 3) causes much difficulty.

The pile group effect was investigated by the senior author in the reference [30] by using the method due to [31]. It was made clear that the pile group effect reduces the soil-pile spring stiffness in general. As shown in Section 6.3, while the increase of the soil-pile spring stiffness leads to the reduction of the pile bending moment due to the inertial effect, it leads to the increase of the pile bending moment due to the kinematic effect. Conversely, when the soil-pile spring stiffness is reduced, the inertial effect is increased and the kinematic effect is reduced. Although the variation of the pile bending moment is insensitive to the change of the soil-pile spring stiffness, it depends on the model of the pile and soil. Furthermore, the ratio of the inertial effect and the kinematic effect also depends on the model of the pile and soil. The result in the reference [30] is concerned with the transfer function, not the earthquake response, and the earthquake response including pile group effects requires the computation in the frequency domain. Simultaneous consideration of the frequencydependent property of a soil-pile spring and its nonlinear elastic-plastic behavior need complicated and difficult task. Therefore the clarification of the superposition rule of the inertial effect and the kinematic effect under the pile group effect may require further investigation.

The effect of rotation of pile head may be a topic of future investigation. It is expected that the placement of a rotational spring at the pile top will enable the consideration of such pile-head rotation.

\section{Conclusions}

The conclusions may be summarized as follows:

(1) A response spectrum method in terms of complex modal quantities can be used in the evaluation of the maximum kinematic and inertial seismic responses (pile-head moment) of a pile-soil model to a ground motion defined at the engineering bedrock surface. 
(2) The kinematic response, the inertial response and the total response can be evaluated by the same analysis model by changing the model parameters. This is an advantageous feature of this paper. Since the forced displacement of the free-field ground (action 1) and the inertial force from the super-structure (action 2) are two major actions, action 1 can be performed by specifying zero masses in the super-structure and foundation and action 2 can be attained by specifying the zero displacement of the free-field ground (by specifying rigid stiffness for free-field ground) with a modification factor for a total inertial force.

(3) The accuracy of the simple (direct) sum or the SRSS of the kinematic response and the inertial response has been investigated numerically for the evaluation of the maximum pile-head moment. The validity of the simple sum or the SRSS depends on the relation between the fundamental natural period of the surface soil ground and that of the superstructure. In the case where the fundamental natural period of the superstructure is shorter than that of the surface ground, the simple sum is appropriate. On the other hand, in the case where the fundamental natural period of the superstructure is longer than that of the surface ground, the SRSS is appropriate. Although this general property is known partially in the practical design $[6,8,9]$, more comprehensive investigation has been conducted.

(4) When the fundamental natural period of a superstructure is close to that of the surface soil ground, the actual total response of the pile-head moment tends to become an average value of the simple sum and the SRSS. Even in this case, the proposed unified response spectrum method plays an important role.

(5) When the nonlinear property of soil is considered, the proposed response spectrum method provides a reasonable accuracy under the damage-limit level input both for the maximum pile bending moment and the distribution in its depth direction. On the other hand, the proposed response spectrum method provides a reasonable accuracy under the safety-limit level input only for the maximum pile bending moment. The distribution in its depth direction exhibits a slightly deteriorated one.

From the viewpoint of the change of the ratio of the inertial effect to the kinematic 
effect between the damage-limit level input and the safety-limit level input, in addition to the variation of soil-pile spring stiffness, the variation of soil-pile dashpot damping plays another important role in the evaluation of such ratio. This fact leads to a complicated situation. Further investigation will be necessary to include this effect in a more reliable manner.

\section{Acknowledgements}

Part of the present work is supported by the Grant-in-Aid for Scientific Research of Japan Society for the Promotion of Science (No.24246095). This support is greatly appreciated.

\section{References}

[1] Gazetas G. and Dobry R., Horizontal response of piles in layered soils, J. Geotech. Eng., ASCE, 1984; 110(1): 20-40.

[2] Kavvadas M and Gazetas G. Kinematic seismic response and bending of free-head piles in layered soil. Geotechnique 1993; 43(2): 207-22.

[3] Miyamoto Y, Fukuoka A, Adachi N and Sako Y. Pile response induced by inertial and kinematic interaction in liquefied soil deposit, J. Structural Construction Engineering, AIJ 1996; 482: 53-62 (in Japanese).

[4] Mylonakis G., Nikolaou A. and Gazetas G. Soil-pile-bridge seismic interaction: Kinematic and inertial effects. Part I; Soft soil, Earthquake Engineering and Structural Dynamics 1997; 26: 337-359.

[5] Boulanger RW, Curras JC, Kuter BL, Wilson DW, Abghari A. Seismic soil-pile-structure interaction experiments and analyses. J Geotech Geoenviron Eng ASCE 1999; 125(9): 750-9.

[6] Murono Y. and Nishimura A. Evaluation of seismic force of pile foundation induced by inertial and kinematic interaction, Proc. 12th World Conference on Earthquake Engineering, Paper No.1496, 2000.

[7] Dobry R, Abdoun T, O’Rourke TD, Goh SH. Single piles in lateral spreads: Field bending moment evaluation. J Geotech Geoenviron Eng ASCE 2003; 129(10): 879-89.

[8] Tokimatsu K., Suzuki H. and Sato M. Effects of dynamic soil-structure interaction on pile 
stress, J. Struct. Construction Eng., AIJ 2005; 587: 125-132 (in Japanese).

[9] Tokimatsu K., Suzuki H. and Sato M. Effects of inertial and kinematic interaction on seismic behavior of pile with embedded foundation, Soil Dynamics and Earthquake Engineering 2005; 25: 753-762.

[10] Kishida A and Takewaki I. Response spectrum method for kinematic soil-pile interaction analysis, Advances in Structural Engineering 2010; 13(1): 181-197.

[11] Ashford S, Boulanger R and Brandenberg S. Recommended design practice for pile foundations in laterally spreading ground, PEER Report, No.PEER 2011/04, 2011.

[12] Takewaki I, Nakamura T and Hirayama K. Seismic frame design via inverse mode design of frame-ground systems, Soil Dynamics and Earthquake Engineering 1998; 17(3): 153163.

[13] Lysmer J, Udaka T, Tsai C-F and Seed HB. FLUSH: A computer program for rapproximate3-D analysis of soil-structure interaction problems, Earthquake Engineering Research Center Report/No. EERC 75-30, Univ. of California, Berkeley, 1975.

[14] Der Kiureghian A. A response spectrum method for random vibrations. Report No. UCB/EERC 80-15, Earthquake Engineering Research Center, Univ. of California, Berkeley, California, USA, 1980.

[15] Wilson EL, Der Kiureghian A and Bayo EP. A replacement for the SRSS method in seismic analysis. Earthquake Engineering and Structural Dynamics 1981; 9: 187-194.

[16] Takewaki I, Murakami S, Fujita K, Yoshitomi S and Tsuji M. The 2011 off the Pacific coast of Tohoku earthquake and response of high-rise buildings under long-period ground motions, Soil Dynamics and Earthquake Engineering 2011; 31(11): 1511-1528.

[17] Takewaki I, Fujita K and Yoshitomi S. Uncertainties in long-period ground motion and its impact on building structural design: Case study of the 2011 Tohoku (Japan) earthquake, Engineering Structures 2013; 49: 119-134.

[18] Schnabel PB, Lysmer J, and Seed HB. SHAKE: A computer program for earthquake response analysis of horizontally layered sites, A computer program distributed by NISEE/ Computer Applications, Berkeley, 1972.

[19] Ching J-Y, and Glaser SD. 1D time-domain solution for seismic ground motion prediction. J. Geotechnical Geoenvironmental Engineering, ASCE 2001; 127(1): 36-47 
[20] Yang JN, Sarkani S and Long FX. Response spectrum approach for seismic analysis of nonclassically damped structures, Engineering Structures 1990; 12: 173-184.

[21] Nakamura T, Takewaki I, Asaoka Y. Sequential stiffness design for seismic drift ranges of a shear building-pile-soil system, Earthquake Engineering and Structural Dynamics 1996; 25(12): 405-420.

[22] Takewaki I. Inverse stiffness design of shear-flexural building models including soilstructure interaction, Engineering Structures 1999; 21(12): 1045-1054.

[23] Takewaki I. Frequency domain analysis of earthquake input energy to structure-pile systems, Engineering Structures 2005; 27(4): 549-563.

[24] Takewaki I. Response spectrum method for nonlinear surface ground analysis, An International Journal of Advances in Structural Engineering 2004; 7(6): 503-514.

[25] Tajimi H. A contribution to theoretical prediction on dynamic stiffness surface foundations. Proc. 7th World Conf. Earthquake Eng., Istanbul, 1980, 105-112.

[26] Tassoulas JL and Kausel E. Elements for the numerical analysis of wave motion in layered strata. Int. J. Numerical Methods in Eng. 1983; 19(7): 1005-1032.

[27] Kausel E. The thin-layer method in seismology and earthquake engineering, in Wave Motion in Earthquake Engineering, WIT Press, 193-213, 2000.

[28] Newmark NM and Hall WJ. Earthquake Spectra and Design, Earthquake Eng. Research Institute, Berkeley, CA, 1982.

[29] Nikolaou, S., Mylonakis, G., Gazetas, G., and Tazoh, T., Kinematic pile bending during earthquakes: analysis and field measurements, Geotechnique, 2001; 51(5): 425-440.

[30] Takewaki, I. and Kishida, A. Efficient analysis of pile-group effect on seismic stiffness and strength design of buildings, Soil Dynamics and Earthquake Engineering 2005; 25(5): 355-367.

[31] Makris N, Gazetas G. Dynamic pile-soil-pile interaction, part II: lateral and seismic response. Earthquake Eng Struct Dyn 1992; 21: 145-162.

\section{Appendix-1}

The equations of motion for the model shown in Fig.6 may be described by

$$
-m_{1}\left(\ddot{u}_{g}+\ddot{u}_{1}\right)-k_{1}\left(u_{1}-u_{0}\right)=0
$$




$$
\begin{aligned}
& -m_{0}\left(\ddot{u}_{g}+\ddot{u}_{0}\right)+k_{1}\left(u_{1}-u_{0}\right)-k_{I}\left(u_{0}-u_{G}\right)-k_{P} u_{0}=0 \\
& -m_{G}\left(\ddot{u}_{g}+\ddot{u}_{G}\right)+k_{I}\left(u_{0}-u_{G}\right)-k_{G} u_{G}=0
\end{aligned}
$$

Since the free-field ground is not influenced by the response of the structure-pile system, it is assumed here that

$$
\begin{aligned}
& m_{G} \gg m_{0}, m_{1} \\
& k_{G} \gg k_{I}, k_{P}, k_{1}
\end{aligned}
$$

The present model can be solved first by obtaining $u_{G}$ from

$$
m_{G} \ddot{u}_{G}+k_{G} u_{G}=-m_{G} \ddot{u}_{g}
$$

Eq.(A3) was derived by applying the assumption of Eq.(A2b) to Eq.(A1c).

For the computed $u_{G}$ and the given $\ddot{u}_{g}$, the remaining response quantities can be derived from

$$
\begin{aligned}
& m_{1} \ddot{u}_{1}+k_{1}\left(u_{1}-u_{0}\right)=-m_{1} \ddot{u}_{g} \\
& m_{0} \ddot{u}_{0}-k_{1}\left(u_{1}-u_{0}\right)+k_{I} u_{0}+k_{P} u_{0}=-m_{0} \ddot{u}_{g}+k_{I} u_{G}
\end{aligned}
$$

This is a multi-input problem from the engineering bedrock and the ground surface.

\section{Appendix-2}

Each soil layer is modeled by a finite-element procedure [10, 21] using a linear displacement function. When a sufficiently small thickness of a soil layer is selected, this element provides a reasonable accuracy. The governing area of the ground is assumed to be unity here. The system mass and stiffness matrices $\mathbf{M}, \mathbf{K}$ are then expressed by

$$
\mathbf{M}=\sum_{i=1}^{N} \mathbf{m}_{i}, \quad \mathbf{K}=\sum_{i=1}^{N} \mathbf{k}_{i}
$$




$$
\mathbf{m}_{i}=\left[\begin{array}{lll}
\ddots & & 0 \\
& \mathbf{m}^{(i)} & \\
0 & & \ddots
\end{array}\right], \mathbf{k}_{i}=\left[\begin{array}{lll}
\ddots & & 0 \\
& \mathbf{k}^{(i)} & \\
0 & & \ddots
\end{array}\right]
$$

where

$$
\mathbf{m}^{(i)}=\left[\begin{array}{ll}
(1 / 3) m_{\text {soil }}^{(i)} & (1 / 6) m_{\text {soil }}^{(i)} \\
(1 / 6) m_{\text {soil }}^{(i)} & (1 / 3) m_{\text {soil }}^{(i)}
\end{array}\right], \mathbf{k}^{(i)}=\left[\begin{array}{cc}
k_{\text {soil }}^{(i)} & -k_{\text {soil }}^{(i)} \\
-k_{\text {soil }}^{(i)} & k_{\text {soil }}^{(i)}
\end{array}\right]
$$

In Eqs.(A6a, b), $\mathbf{m}_{i}$ and $\mathbf{k}_{i}$ are the element mass and stiffness matrices, respectively, of the $i$ th layer and $m_{\text {soil }}^{(i)}=\rho_{i} h_{i}, k_{\text {soil }}^{(i)}=G_{i} / h_{i}$.

The damping matrix $\mathbf{C}$ is described by

$$
\mathbf{C}=\sum_{i=1}^{N}\left(\frac{2 \beta_{i}}{\omega_{G 1}}\right) \mathbf{k}_{i}+\mathbf{C}_{b}
$$

where $\omega_{G 1}$ is the fundamental natural circular frequency of the surface ground and $\mathbf{C}_{b}$ is the element damping matrix consisting of the damping coefficient $\sqrt{\rho_{N} G_{N}}$ of the viscous boundary at the bottom of the surface ground.

Let $\Lambda^{(j)}$ and $\mathbf{u}^{(j)}$ denote the $j$-th complex eigenvalue and the $j$-th complex eigenvector of the ground system. The governing equation of the $j$-th damped free vibration may be given by

$$
\left(\Lambda^{(j) 2} \mathbf{M}+\Lambda^{(j)} \mathbf{C}+\mathbf{K}\right) \mathbf{u}^{(j)}=\mathbf{0} .
$$

The eigenvectors $\mathbf{u}^{(j)}$ satisfy the following conditions of orthogonality.

$$
\begin{aligned}
& \left(\Lambda^{(r)}+\Lambda^{(s)}\right) \mathbf{u}^{(r) T} \mathbf{M} \mathbf{u}^{(s)}+\mathbf{u}^{(r) T} \mathbf{C} \mathbf{u}^{(s)}=0(r \neq s) \\
& \Lambda^{(r)} \Lambda^{(s)} \mathbf{u}^{(r) T} \mathbf{M} \mathbf{u}^{(s)}+\mathbf{u}^{(r) T} \mathbf{K} \mathbf{u}^{(s)}=0(r \neq s)
\end{aligned}
$$

The superscript $T$ denotes the transpose of a vector.

Let $\Lambda^{(j)}$ and $\mathbf{u}^{(j)}$ be expressed as

$$
\begin{aligned}
& \Lambda^{(j)}=\alpha^{(j)}+\beta^{(j)_{\mathbf{i}}} \\
& \mathbf{u}^{(j)}=\boldsymbol{\Phi}^{(j)}+\boldsymbol{\Psi}^{(j)_{\mathbf{i}}}
\end{aligned}
$$


where $\mathrm{i}$ is the imaginary unit. The following condition of normalization is employed.

$$
\begin{aligned}
& \boldsymbol{\Phi}^{(j)^{T}} \mathbf{M} \boldsymbol{\Phi}^{(j)}+\Psi^{(j)^{T}} \mathbf{M} \Psi^{(j)}=1 \\
& \boldsymbol{\Phi}^{(j)^{T}} \mathbf{M} \Psi^{(j)}=0
\end{aligned}
$$

Eq.(A12a) is equivalent to $\overline{\mathbf{u}}^{(j)^{T}} \mathbf{M} \mathbf{u}^{(j)}=1\left(\overline{\mathbf{u}}^{(j)}\right.$; the complex conjugate of $\left.\mathbf{u}^{(j)}\right)$ and Eq.(A12b) is another normalization condition independent of Eq.(A12a). From these conditions, the vectors $\boldsymbol{\Phi}^{(j)}$ and $\Psi^{(j)}$ can be determined.

For the sake of compact expression, the following complex participation factor for the $j$ th eigenvibration is introduced [10, 21].

$$
v^{(j)}=\frac{\mathbf{u}^{(j) T} \mathbf{M} \mathbf{1}}{\mathbf{u}^{(j) T} \mathbf{M} \mathbf{u}^{(j)}} \frac{1}{1+\chi^{(j)_{i}}},
$$

where $\mathbf{1}=\{1 \cdots 1\}^{T}$ and

$$
\chi^{(j)}=\frac{h^{(j)}}{\sqrt{1-h^{(j) 2}}}-\frac{1}{2 \omega_{d}} \frac{\mathbf{u}^{(j) T} \mathbf{C} \mathbf{u}^{(j)}}{\mathbf{u}^{(j) T} \mathbf{M} \mathbf{u}^{(j)}}
$$

The pseudo damping factor $h^{(j)}$ and the pseudo natural frequency $\omega^{(j)}$ for the $j$-th eigenvibration may be defined as

$$
\begin{aligned}
& h^{(j)}=\overline{\mathbf{u}}^{(j)^{T}} \mathbf{C} \mathbf{u}^{(j)} /\left(2 \omega^{(j)}\right) \\
& \omega^{(j)^{2}}=\overline{\mathbf{u}}^{(j)^{T}} \mathbf{K} \mathbf{u}^{(j)}
\end{aligned}
$$

The parameters $\alpha^{(j)}$ and $\beta^{(j)}$ in equation (A11a) may be expressed as $\alpha^{(j)}=-\omega^{(j)} h^{(j)}$ and $\beta^{(j)}= \pm \omega^{(j)} \sqrt{1-h^{(j)^{2}}}$ in terms of $h^{(j)}$ and $\omega^{(j)}$.

$$
\begin{aligned}
& \delta_{s k}^{(i)}, \delta_{c k}^{(i)}, \rho_{s s}^{(i j)}, \rho_{c c}^{(i j)}, \rho_{s c}^{(i j)} \text { in Eq.(5) are as follows: } \\
& \delta_{s k}^{(i)}=S_{D s}^{(i)} \operatorname{Re}\left[v^{(i)}\left\{u_{k}^{(i)}-u_{k-1}^{(i)}\right\}\right] \\
& \delta_{c k}^{(i)}=S_{D c}^{(i)} \operatorname{Im}\left[v^{(i)}\left\{u_{k}^{(i)}-u_{k-1}^{(i)}\right\}\right] . \\
& \rho_{s s}^{(i j)}=8 a_{i j} c_{i j} \omega^{(i)} \omega^{(j)} / d_{i j} \\
& \left.\rho_{c c}^{(i j)}=4 a_{i j} b_{i j} c_{i j} /\left\{d_{i j} \sqrt{\left(1+h^{(i)^{2}}\right)\left(1+h^{(j)^{2}}\right.}\right)\right\}
\end{aligned}
$$




$$
\rho_{s c}^{(i j)}=4 a_{i j} \omega^{(i)}\left(b_{i j}-2 \omega_{D}^{(j)^{2}}\right) /\left(d_{i j} \sqrt{1+h^{(j)^{2}}}\right)
$$

$\rho_{s s}^{(i j)}$ denotes the correlation coefficient between the mode $i$ and the mode $j$ in the sine-sine spectrum. $\rho_{s c}^{(i j)}$ indicates that in the sine-cosine spectrum and $\rho_{c c}^{(i j)}$ denotes that in the cosinecosine spectrum. $\operatorname{Re}[\cdot]$ and $\operatorname{Im}[\cdot]$ denote the real and imaginary parts, respectively, of a complex number. The parameters $a_{i j}, b_{i j}, c_{i j}, d_{i j}$ in Eq.(A17) can be defined by

$$
\begin{aligned}
& a_{i j}=\sqrt{h^{(i)} h^{(j)} \omega^{(i)} \omega^{(j)}}, b_{i j}=\omega^{(i)^{2}}+\omega^{(j)^{2}}+2 h^{(i)} h^{(j)} \omega^{(i)} \omega^{(j)}, \\
& c_{i j}=h^{(i)} \omega^{(i)}+h^{(j)} \omega^{(j)}, d_{i j}=b_{i j}{ }^{2}-4 \omega_{D}{ }^{(i)}{ }^{2} \omega_{D}{ }^{(j)^{2}}
\end{aligned}
$$

Furthermore the sine spectrum $S_{D s}^{(i)}$ and cosine spectrum $S_{D c}^{(i)}$ in Eq.(A16) are the mean values of $\max _{t}\left[S_{i}(t)\right], \max _{t}\left[C_{i}(t)\right]$, respectively. Here $S_{i}(t), C_{i}(t)$ are defined by

$$
\begin{aligned}
& S_{i}(t)=\int_{0}^{t} g^{(i)}(t-\tau) \ddot{u}_{g}(\tau) d \tau \\
& C_{i}(t)=\int_{0}^{t} g^{(i)^{*}}(t-\tau) \ddot{u}_{g}(\tau) d \tau
\end{aligned}
$$

where

$$
\begin{aligned}
& g^{(i)}(t)=-\frac{1}{\omega_{D}{ }^{(i)}} e^{-h^{(i)} \omega^{(i)}(t)}\left\{\sin \omega_{D}{ }^{(i)}(t)\right\} \\
& g^{(i)^{*}}(t)=-\frac{1}{\omega_{D}^{(i)}} e^{-h^{(i)} \omega^{(i)}(t)}\left\{\cos \omega_{D}^{(i)}(t)\right\}
\end{aligned}
$$

$S_{D s}^{(i)}$ is equivalent to the displacement response spectrum and $S_{D c}^{(i)}$ is assumed to be also equivalent to the latter. This assumption seems to be valid in the period range to be discussed here. The parameter $u_{k}^{(i)}$ in Eq.(A16) denotes the component in the $i$-th complex eigenvector $\mathbf{u}^{(i)}$ corresponding to the $k$-th nodal displacement $u_{k}$ and $\omega_{D}^{(i)}=\omega^{(i)} \sqrt{1-h^{(i)^{2}}}$.

\section{Appendix-3}

In order to investigate the accuracy and reliability of the present response spectrum method, a comparison has been made for an actual building with piles [29]. The overview of the building-pile model in Yokohama, Japan is shown in Fig.24. This steel-frame building 
consists of 12 stories and is supported by 20 cast-in-place reinforced concrete piles, 35m long and $1.7 \mathrm{~m}$ in diameter. To compare the peak response of bending strains of piles, an overall interaction system as shown in Fig.5(b) has been used. This overall interaction model includes the present Winkler-type soil element and the difference is the shape functions for the free-field ground and piles, i.e. a linear function for the free-field ground and a cubic function for the piles. Fig.25(a) shows the shear wave velocity profile of the ground. Fig.25(b) illustrates the comparison of the peak pile bending strain computed by the analytical model including the present Winkler-type soil element with that recorded during an earthquake in 1992. A fairly good agreement can be observed near the pile head and this demonstrates the validity of the present response spectrum method. This bending strain contains both the inertial effect and the kinematic effect. It may also be said that the pilegroup effect is rather small in this case. 
Action 1

(forced displacement of free-field ground:

kinematic effect)
Action 2

(Inertial force:

Inertial effect)

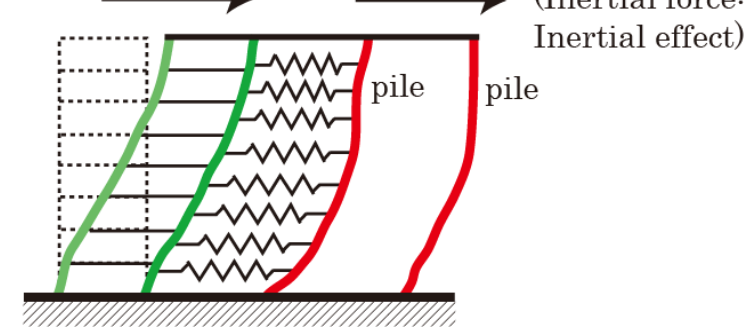

Fig.1 Effect of the forced displacement of free-field ground (action 1) and the effect of the inertial force from superstructure (action 2)
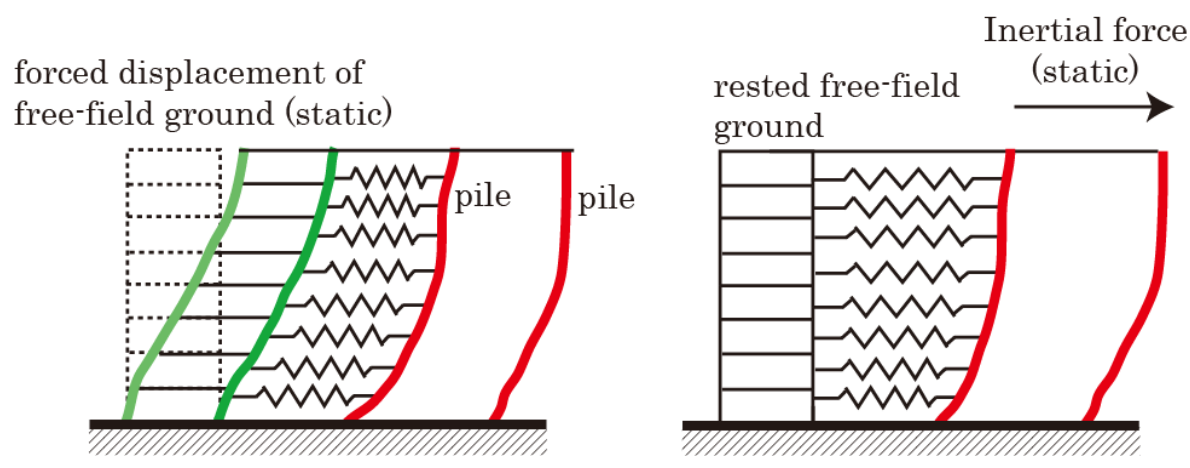

Fig.2 Kinematic effect and inertial effect in the evaluation of pile-head moment in the conventional static method

forced displacement of free-field $\begin{array}{ll}\text { ground } & \text { zero } \\ \text { (dynamic) } & \text { mass }\end{array}$

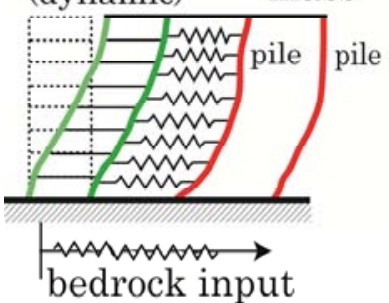

kinematic effect

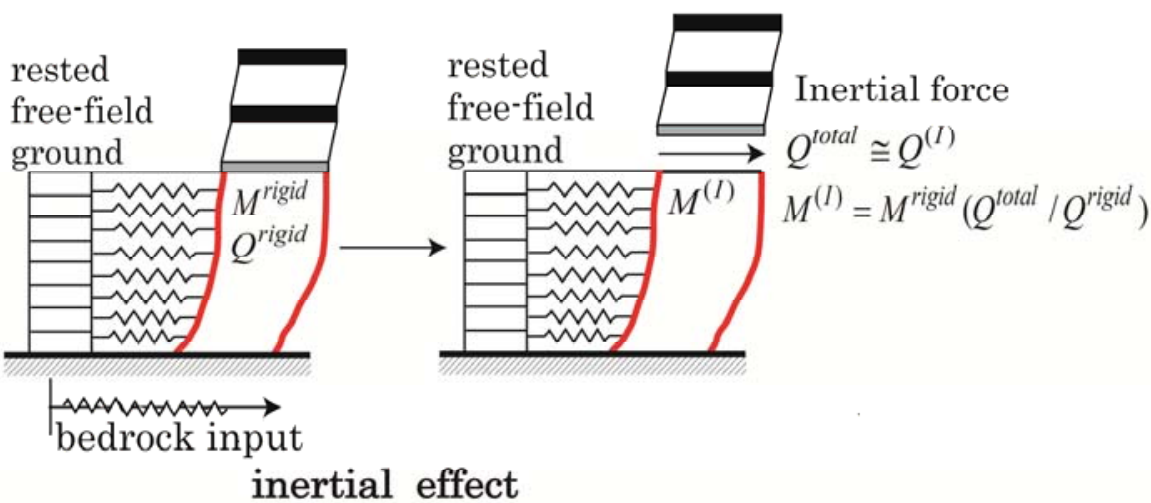

inertial effect

Fig.3 Kinematic effect and inertial effect in the evaluation of pile-head moment in the dynamic method 


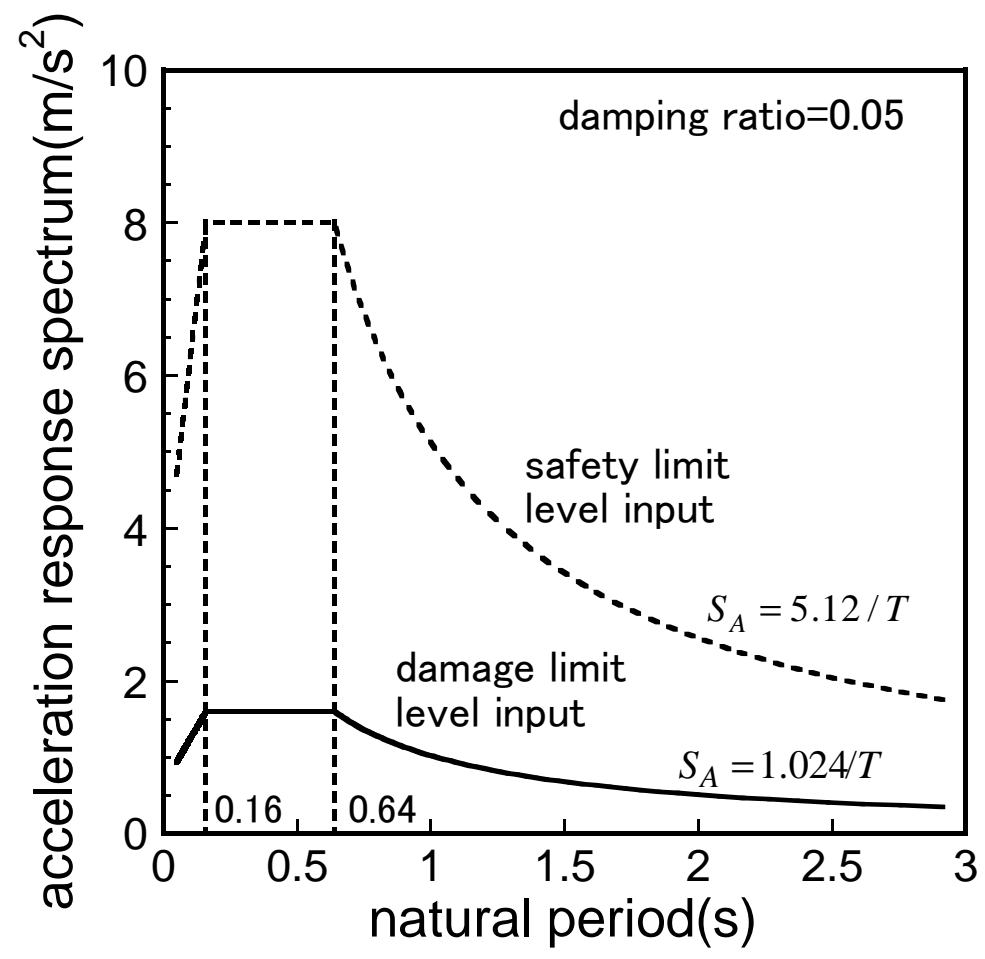

Fig.4 Two-level acceleration response spectra at engineering bedrock surface for the evaluation of the seismic safety of low and medium-rise buildings lower than $60 \mathrm{~m}$ in Japanese seismic-resistant design code (Standard Building Law in Japan)

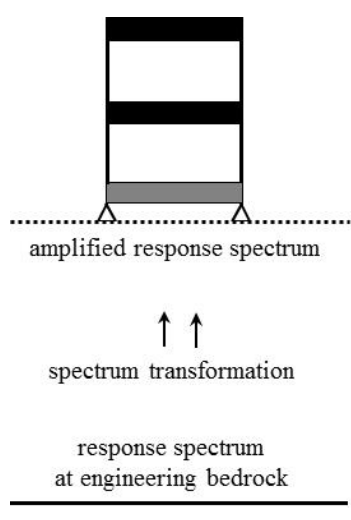

(a)

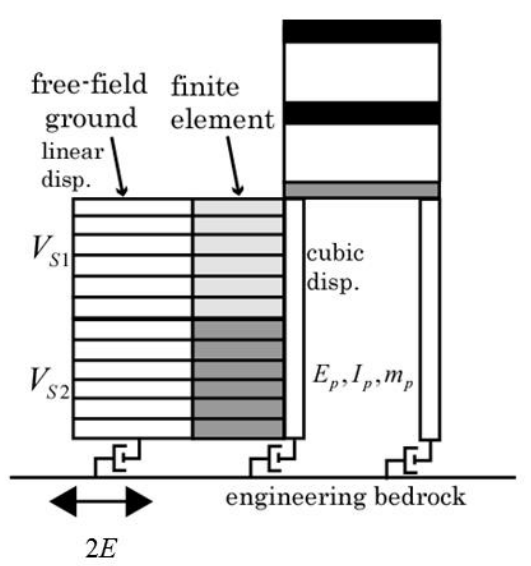

(b)

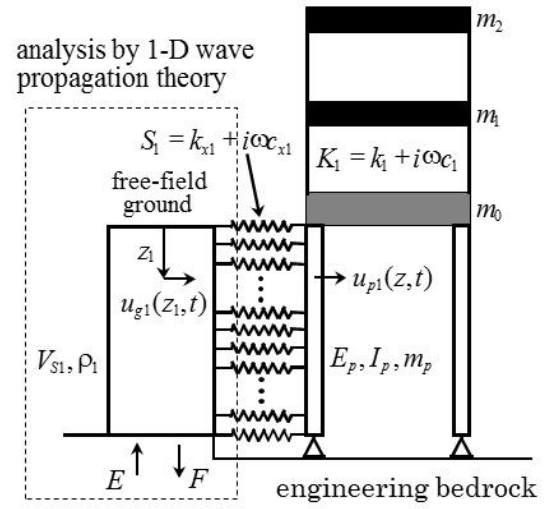

(c)

Fig.5 Three approaches to using acceleration response spectra the engineering bedrock surface; (a) Amplification of response spectrum, (b) Overall interaction system, (c) Substructure model subjected to multiple inputs 


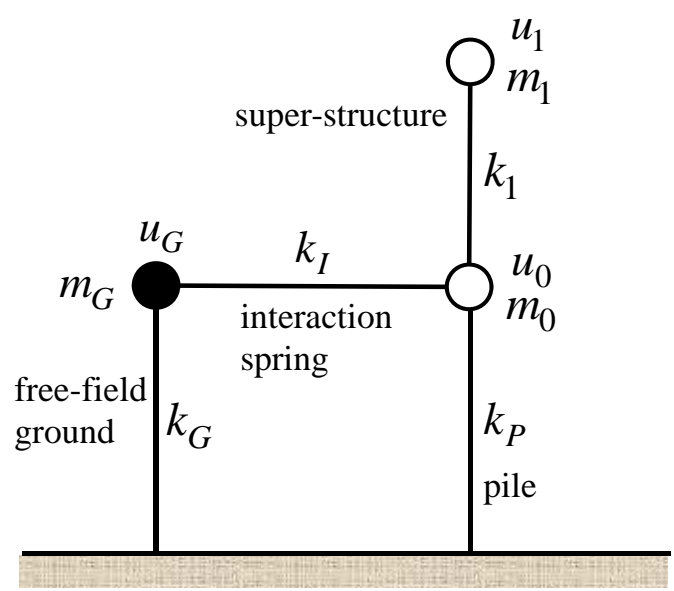

Fig.6 Simple structure-pile-soil system connected to free-field ground
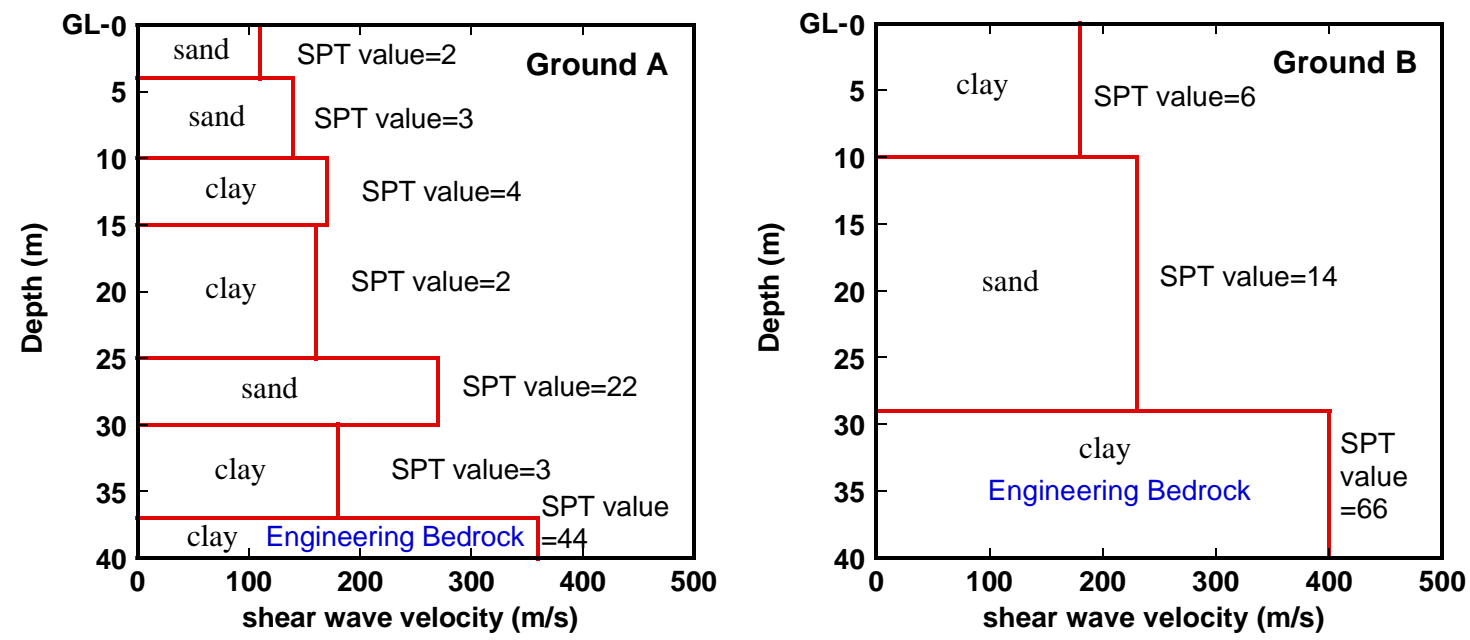

Fig.7 Soil profiles of two ground models A and B and SPT values [10]

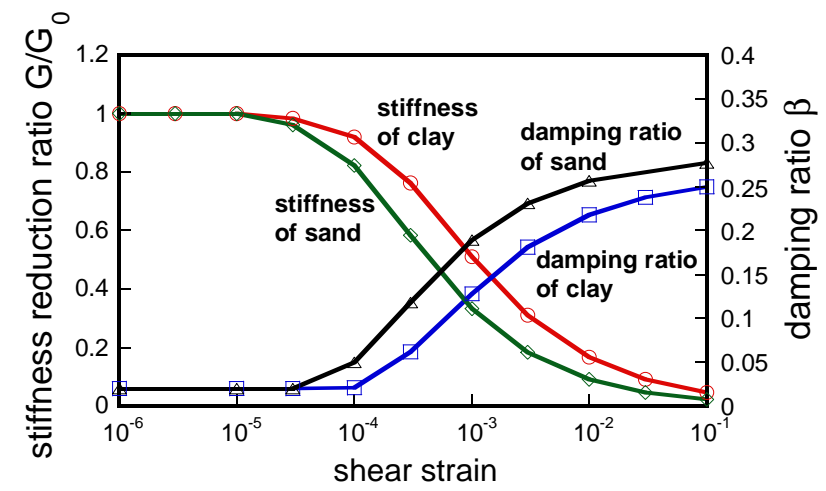

Fig.8 Dependence of shear moduli and damping ratios on the strain level [24] 

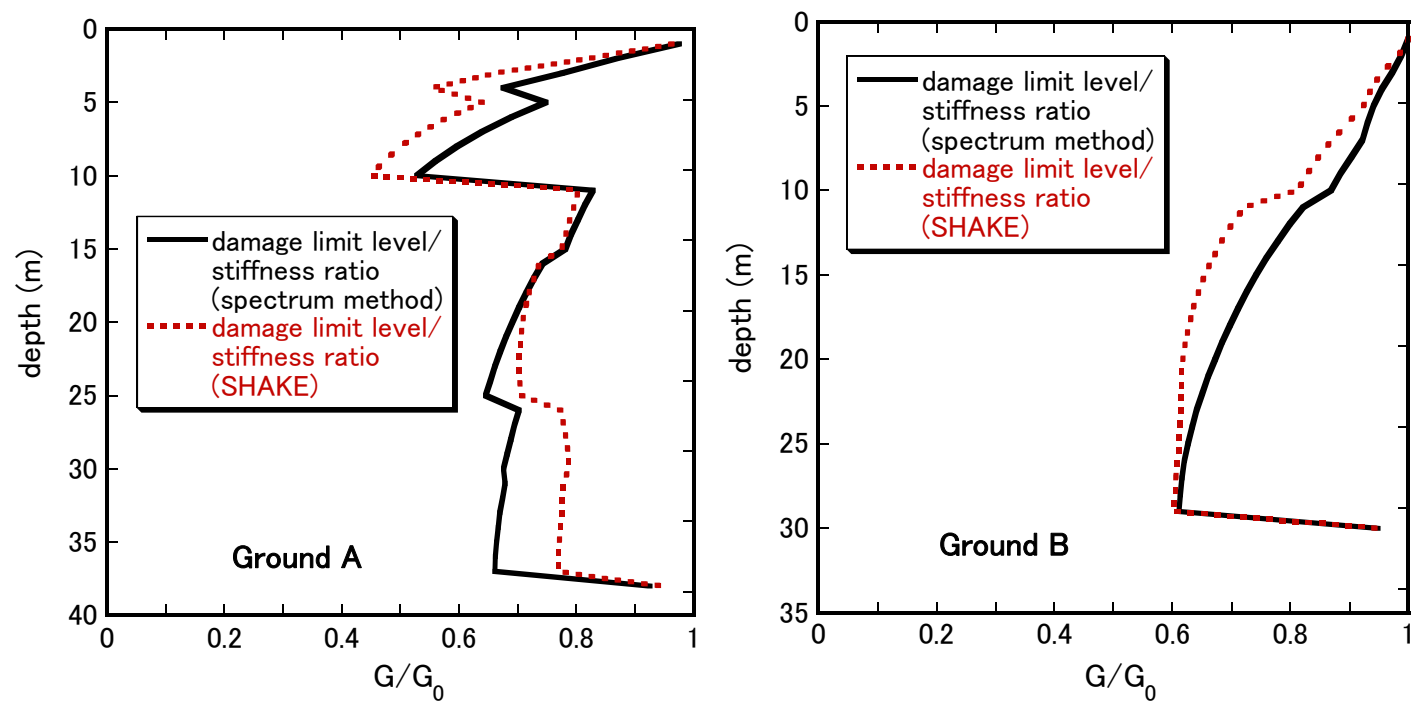

Fig.9 Convergent shear modulus ratio to the initial one (damage limit level): response spectrum method and SHAKE for one simulated motion [24]
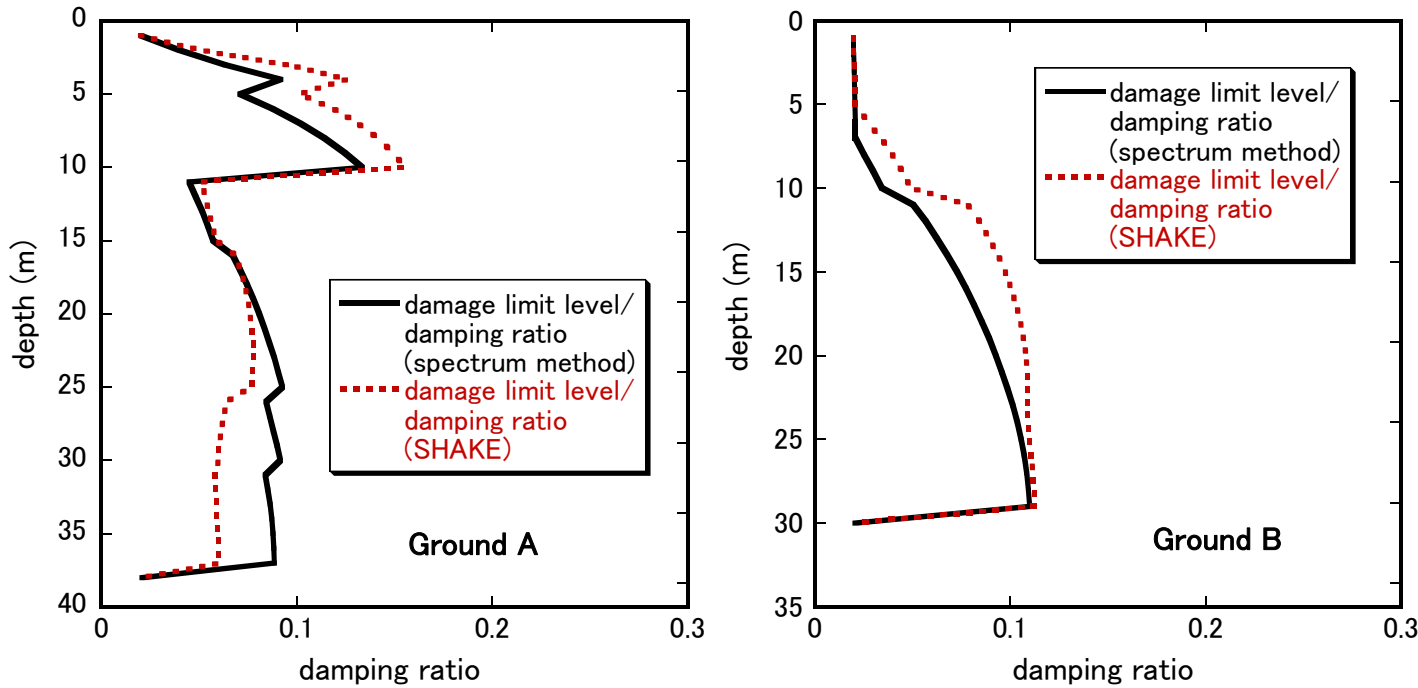

Fig.10 Convergent damping ratio (damage limit level): response spectrum method and SHAKE for one simulated motion [24] 


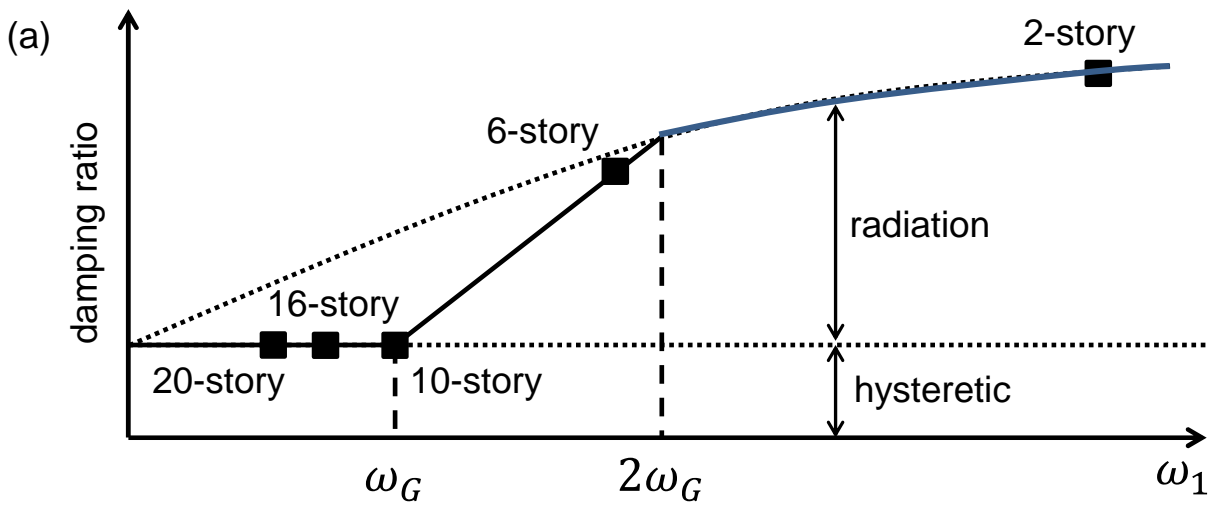

(b)

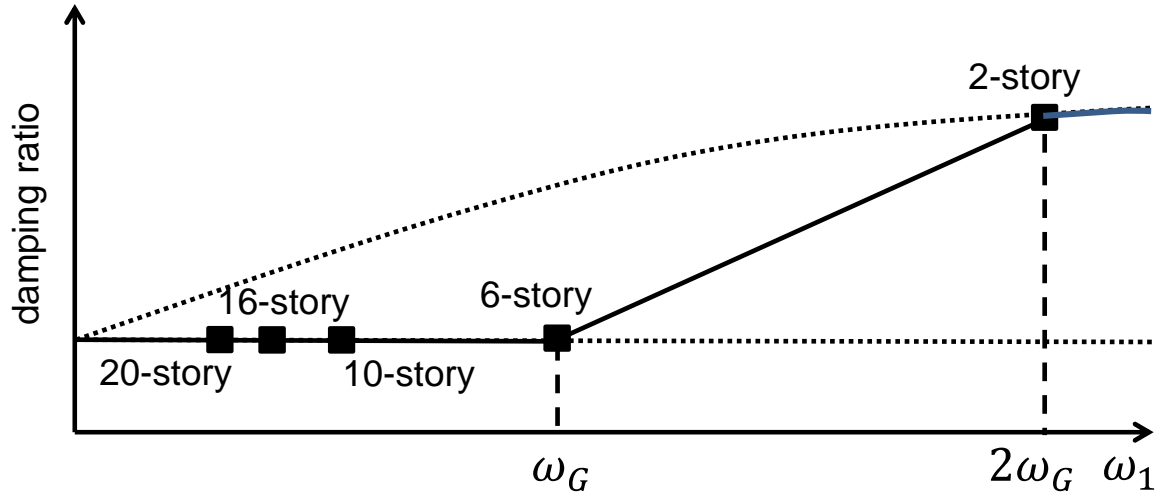

Fig.11 Relation between the fundamental natural period of the ground and that of the building model and the constituents of damping mechanisms: (a) Ground model A, (b) Ground model B 

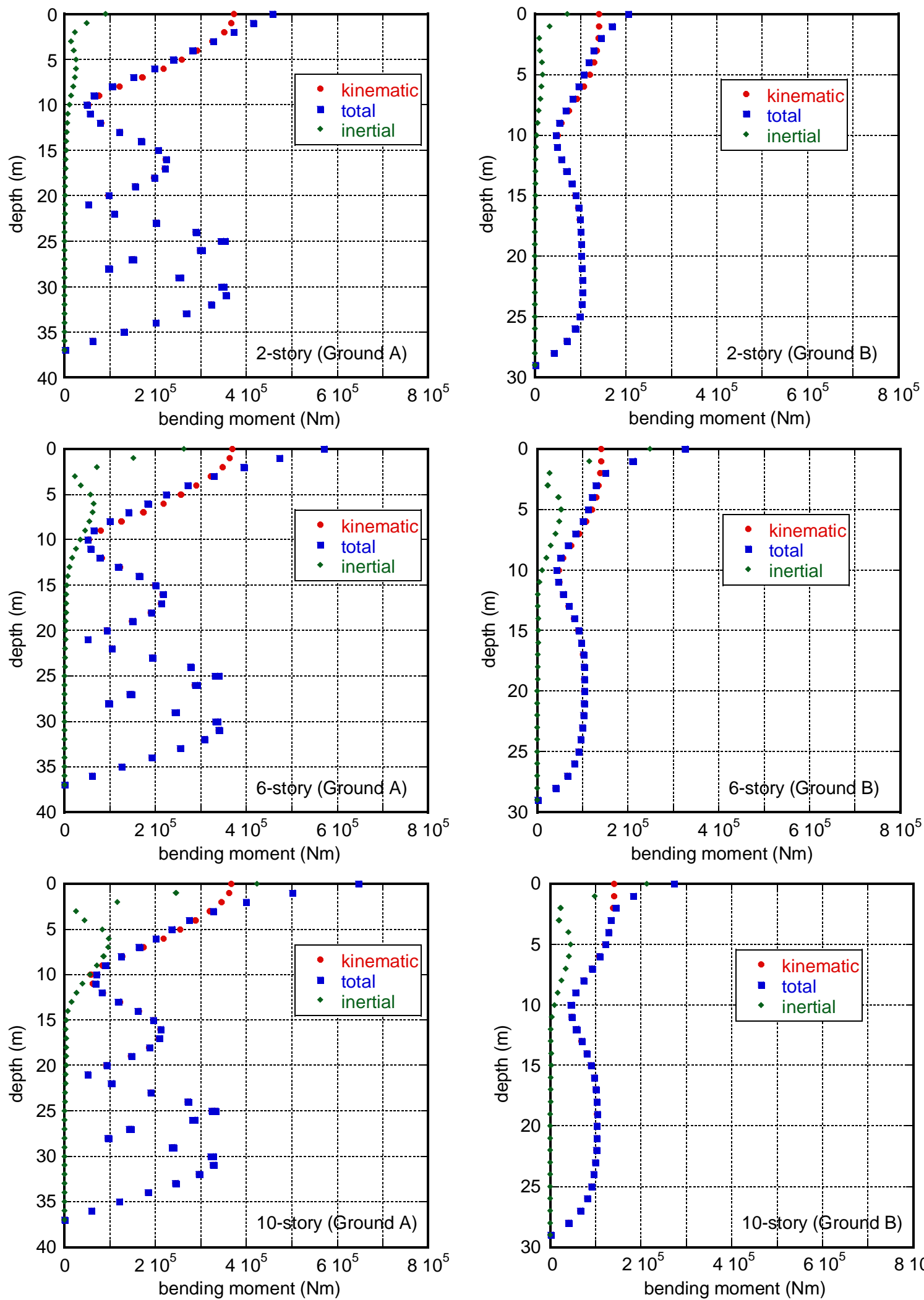

(a) Ground A

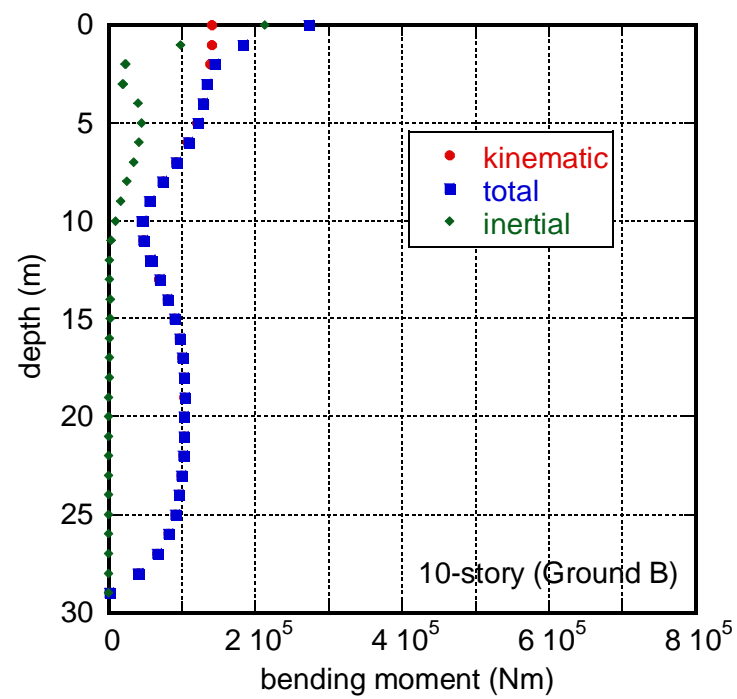

(b) Ground B

Fig.12 Maximum bending moment distribution of the pile due to the kinematic response, the inertial response and their total response 

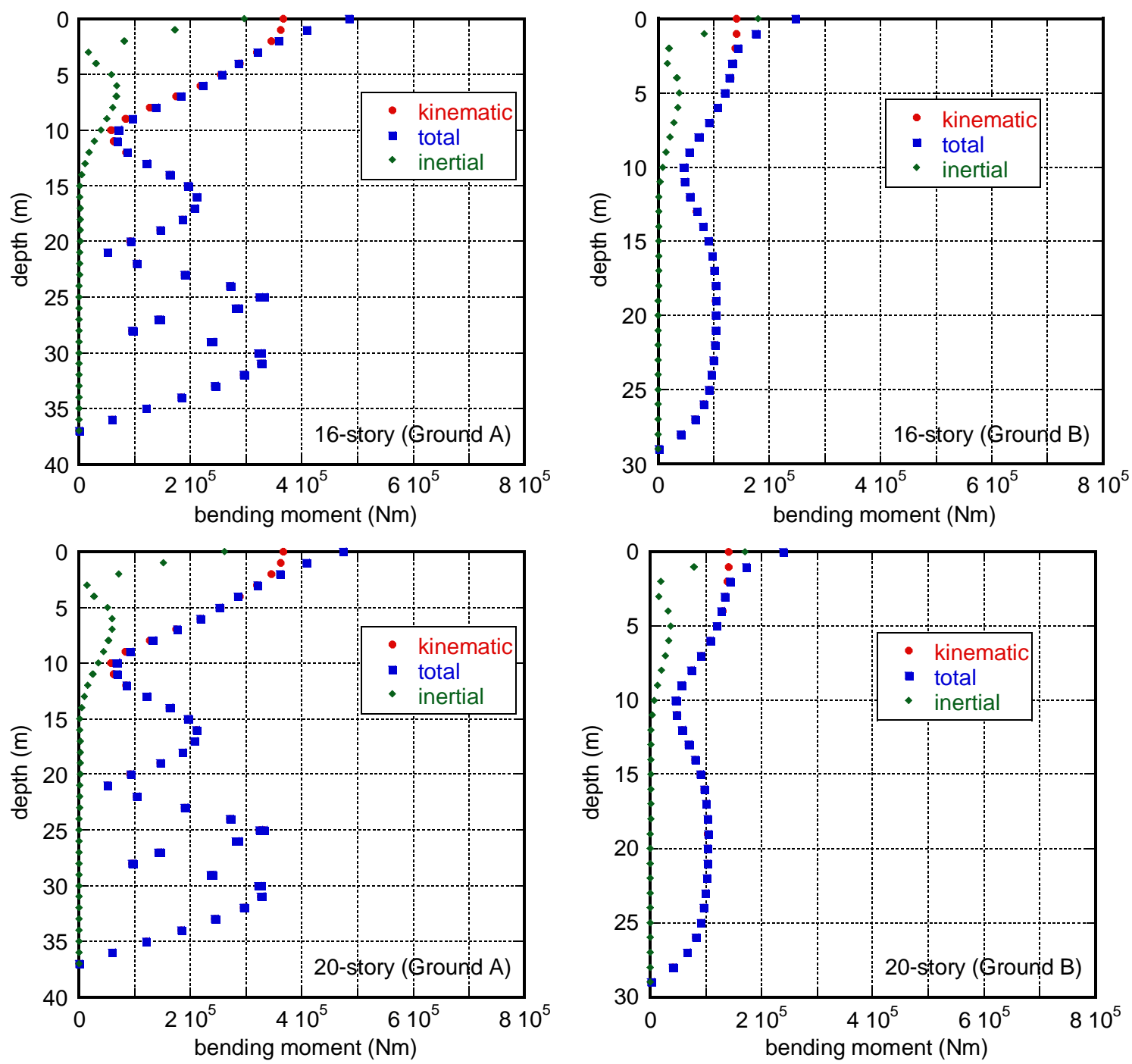

(a) Ground A

(b) Ground B

Fig.12 (Continued) Maximum bending moment distribution of the pile due to the kinematic response, the inertial response and their total response 

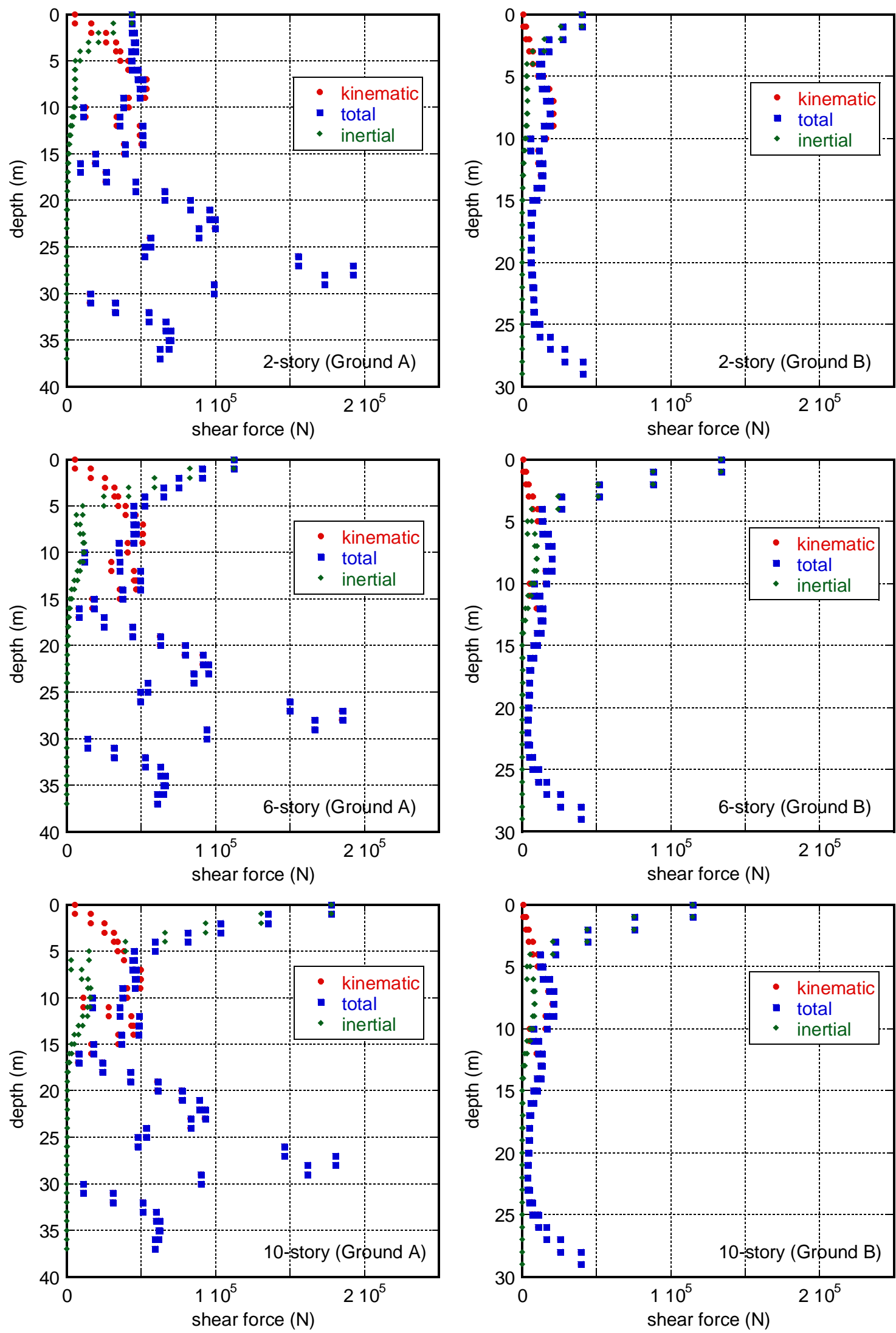

(a) Ground A

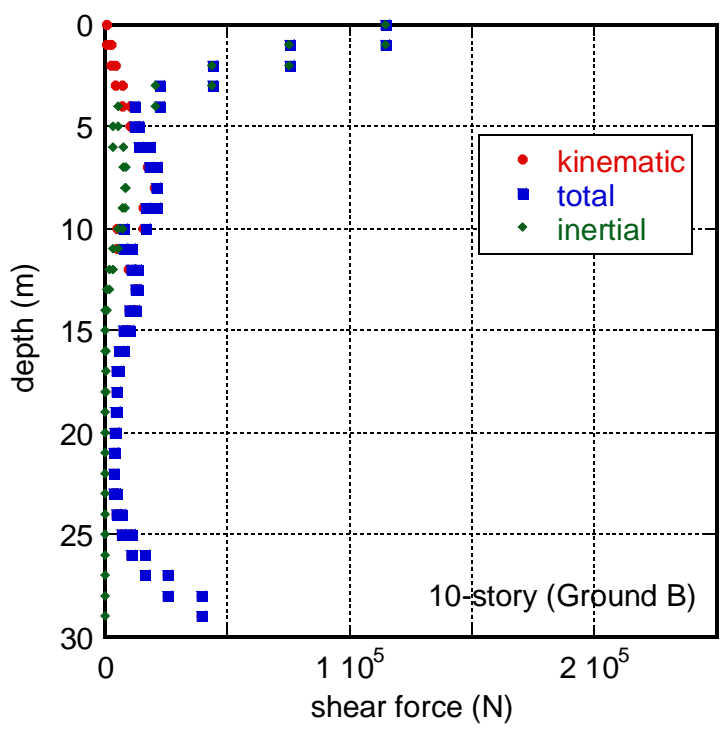

(b) Ground B

Fig.13 Maximum shear force distribution of the pile due to the kinematic response, the inertial response and their total response 

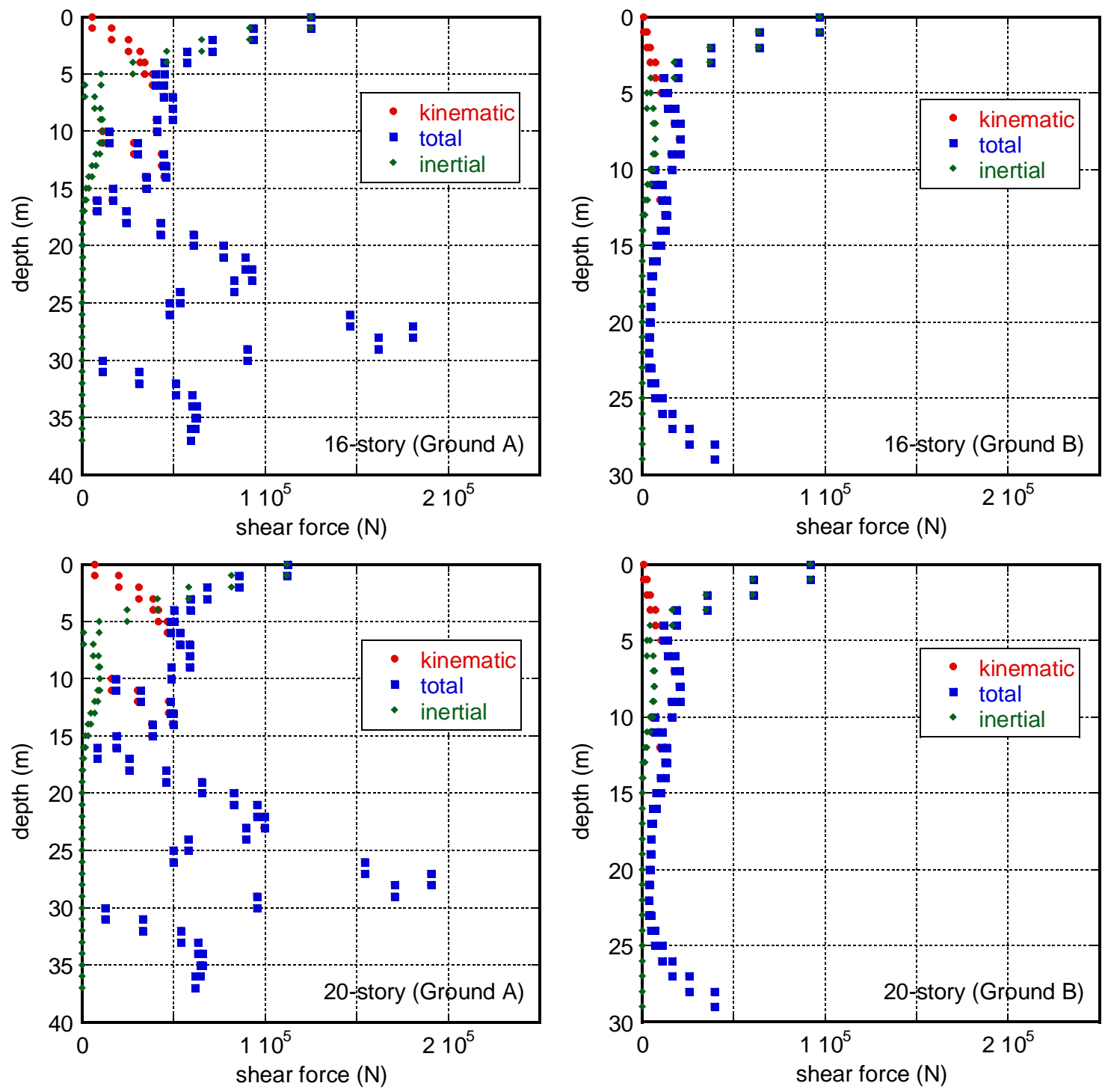

(a) Ground A

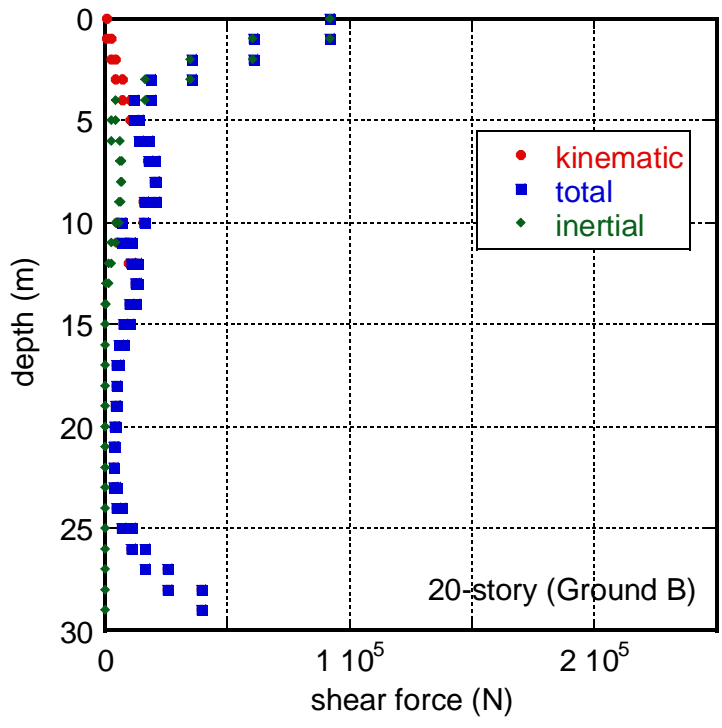

(b) Ground B

Fig.13 (Continued) Maximum shear force distribution of the pile due to the kinematic response, the inertial response and their total response 


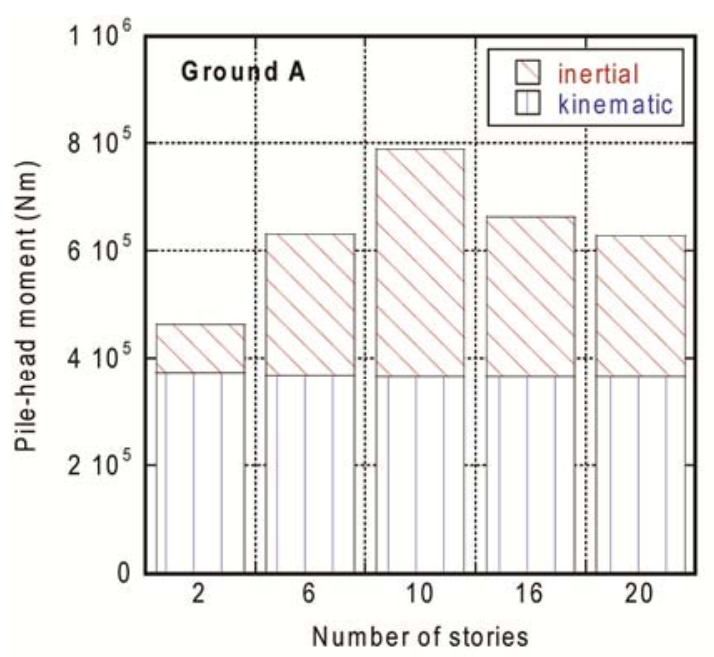

(a) Ground A

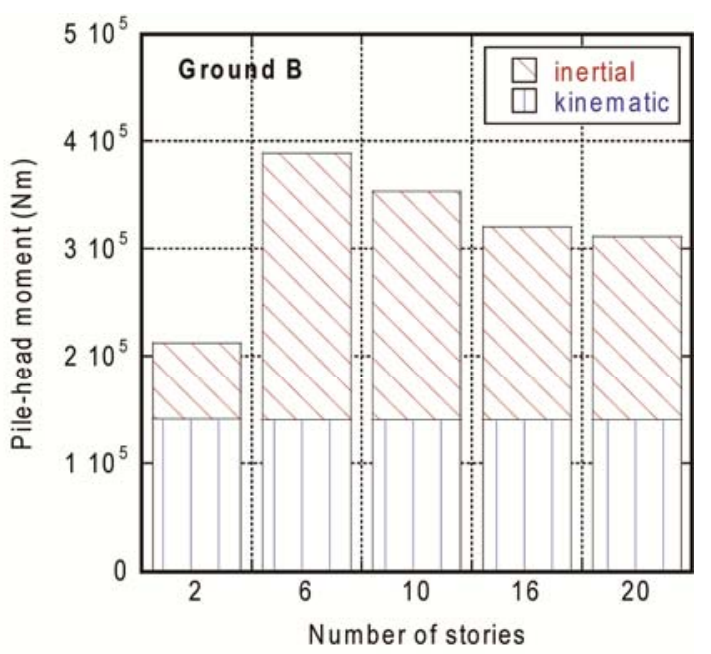

(b) Ground B

Fig.14 Maximum pile-head bending moment due to the kinematic effect and that due to the inertial effect for 2, 5, 10, 16 and 20-story buildings with pile diameter 1.5m (Ground A and Ground B)

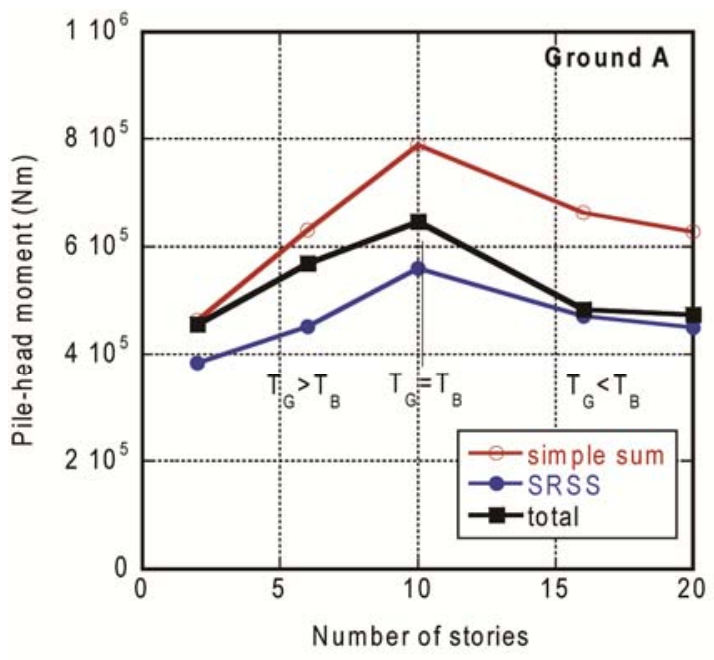

(a) Ground A

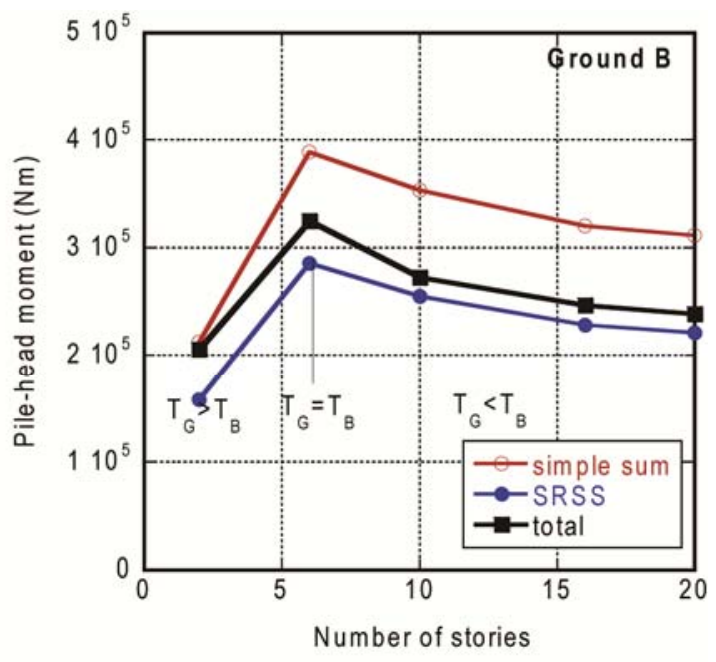

(b) Ground B

Fig.15 Comparison of the maximum pile-head bending moment for pile diameter 1.5m among

(i) simple (direct) sum of kinematic and inertial responses, (ii) SRSS of kinematic and inertial responses and (iii) total (true) one 


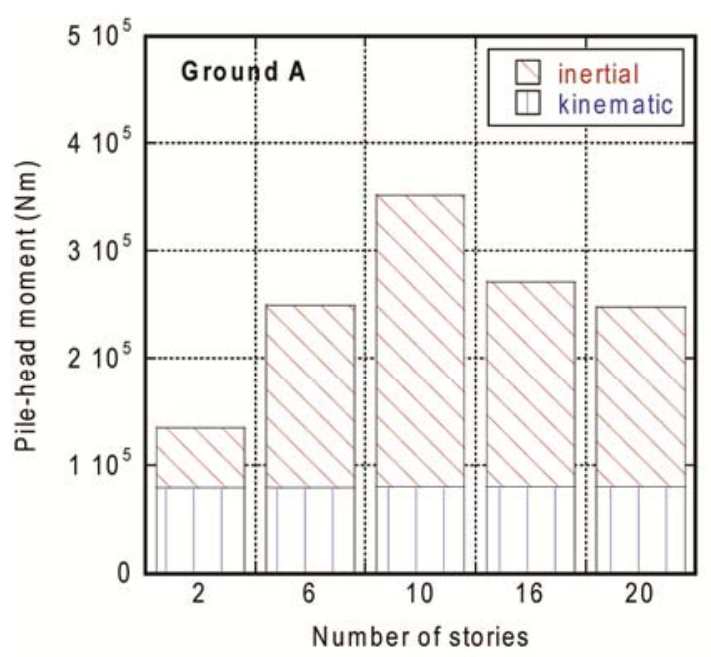

(a) Ground A

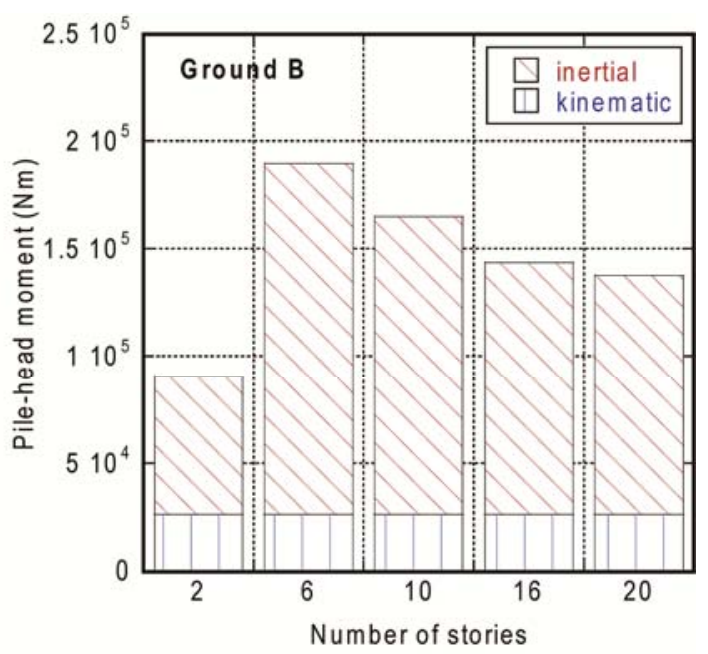

(b) Ground B

Fig.16 Maximum pile-head bending moment due to the kinematic effect and that due to the inertial effect for 2, 5, 10, 16 and 20-story buildings with pile diameter 1.0m (Ground A and Ground B)

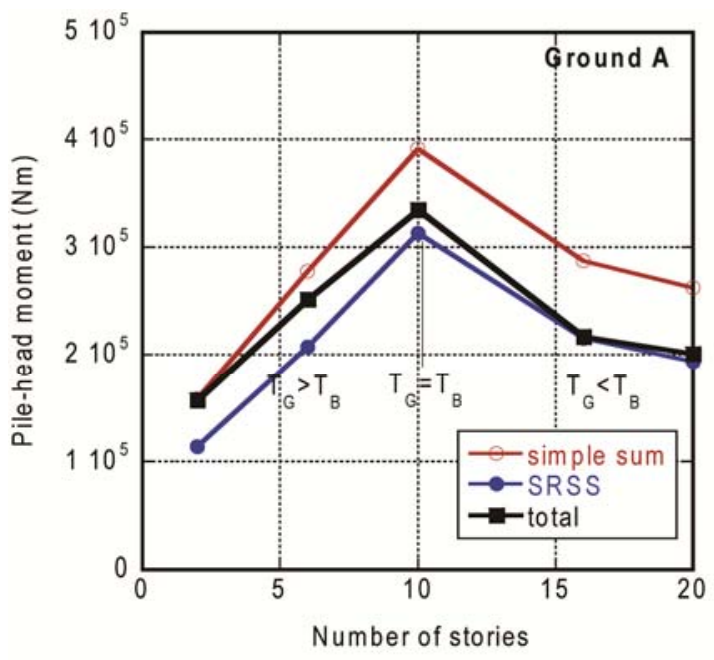

(a) Ground A

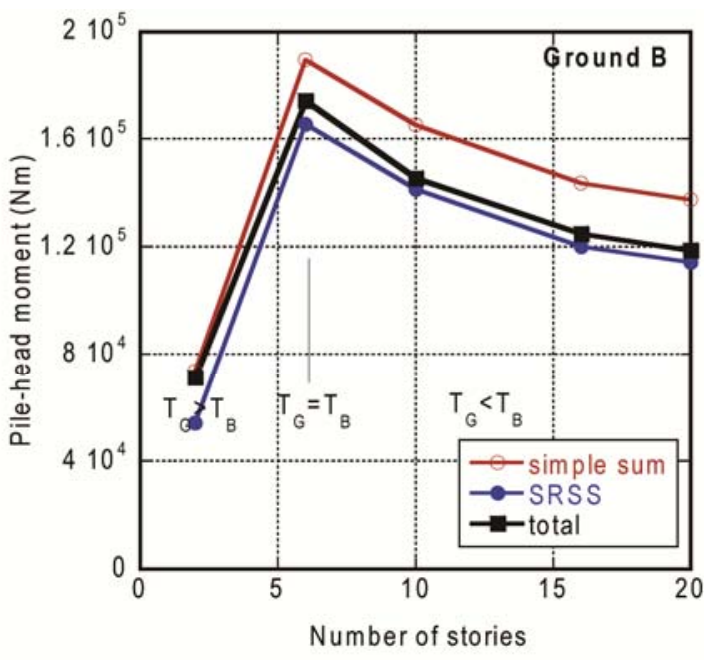

(b) Ground B

Fig.17 Comparison of the maximum pile-head bending moment for pile diameter 1.0m among (i) simple sum of kinematic and inertial responses, (ii) SRSS of kinematic and inertial responses and (iii) total (true) one 


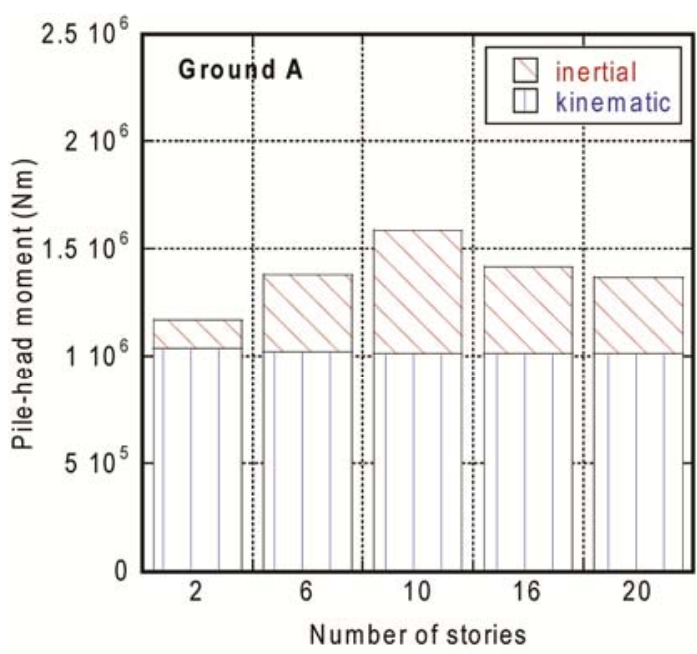

(a) Ground A

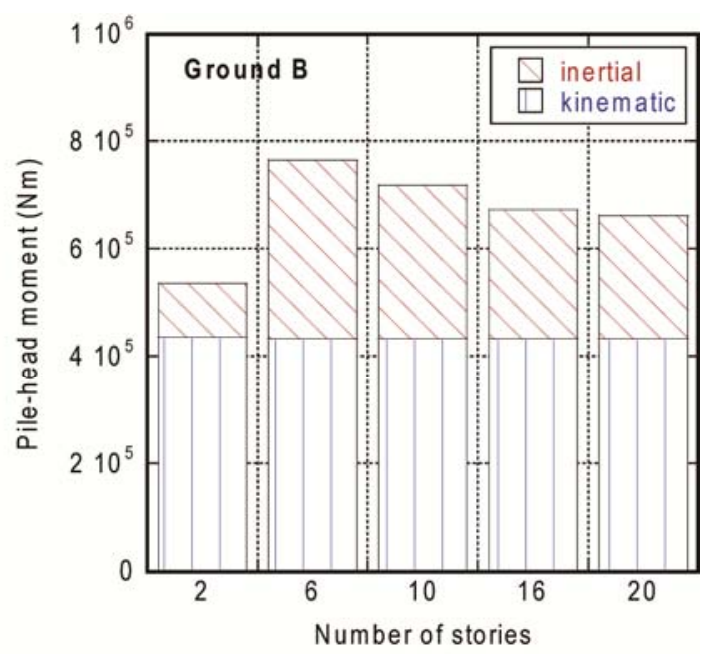

(b) Ground B

Fig.18 Maximum pile-head bending moment due to the kinematic effect and that due to the inertial effect for 2, 5, 10, 16 and 20-story buildings with pile diameter 2.0m (Ground A and Ground B)

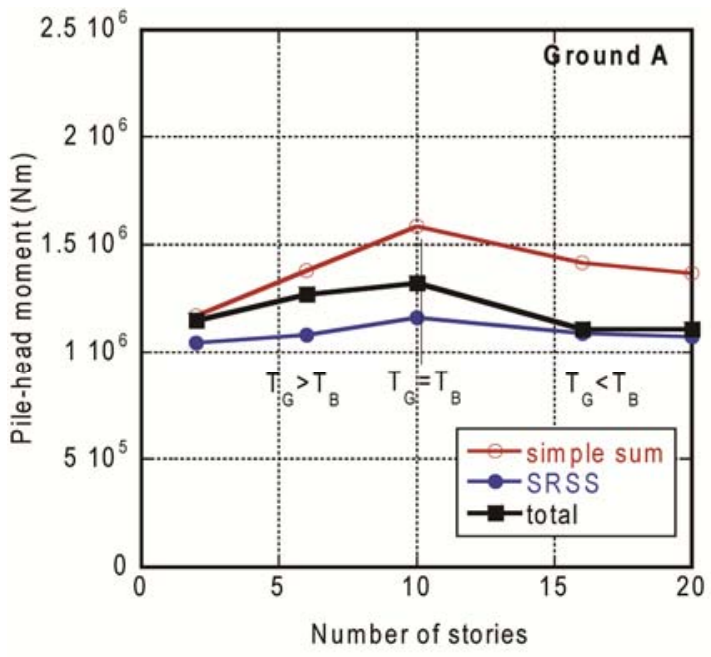

(a) Ground A

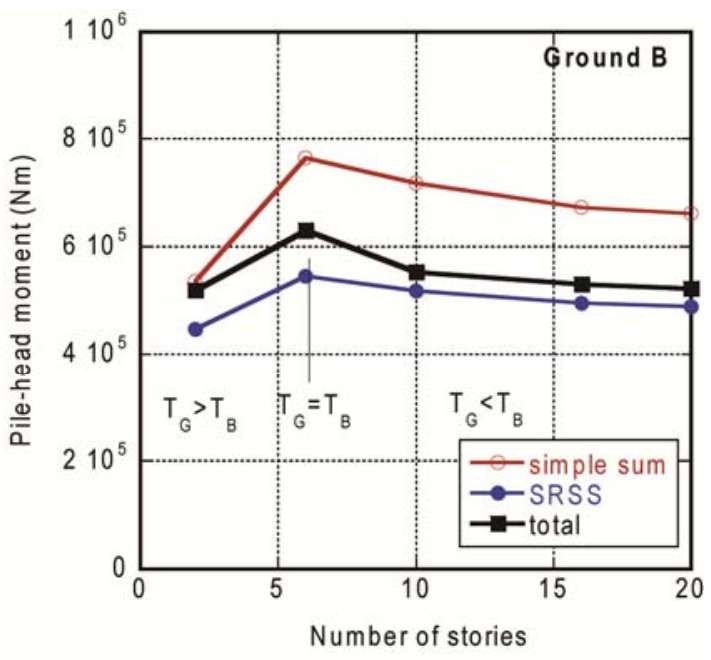

(b) Ground B

Fig.19 Comparison of the maximum pile-head bending moment for pile diameter 2.0m among (i) simple sum of kinematic and inertial responses, (ii) SRSS of kinematic and inertial responses and (iii) total (true) one 

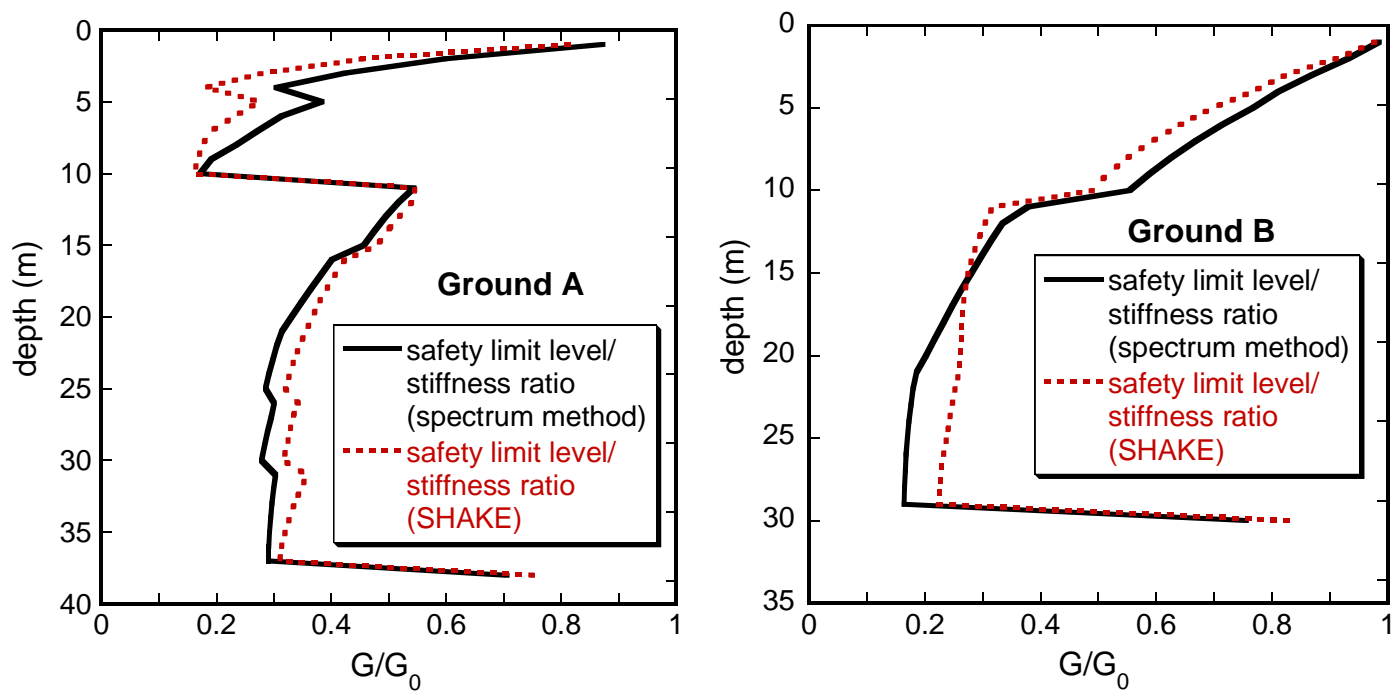

Fig.20 Convergent shear modulus ratio to the initial one (safety limit level) : response spectrum method and SHAKE for one simulated motion [24]
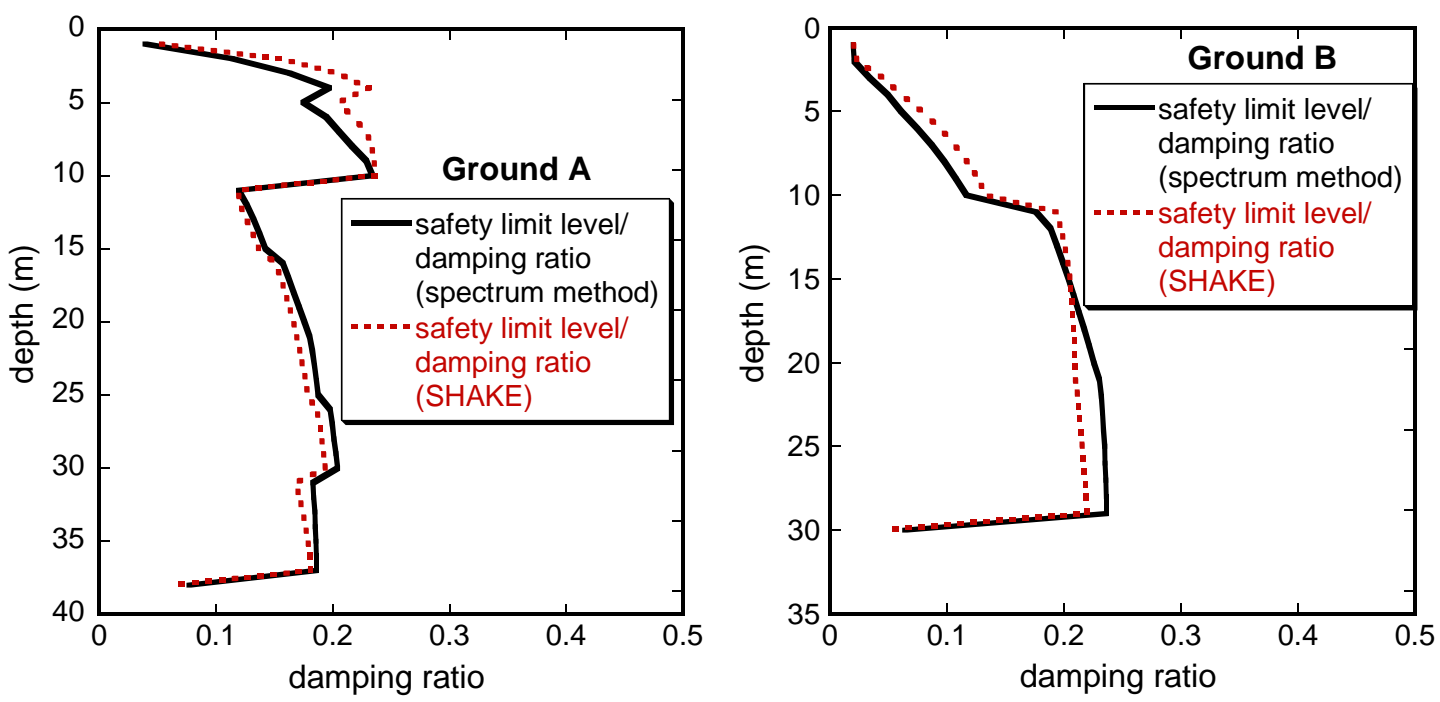

Fig.21 Convergent damping ratio (safety limit level) : response spectrum method and SHAKE for one simulated motion [24] 


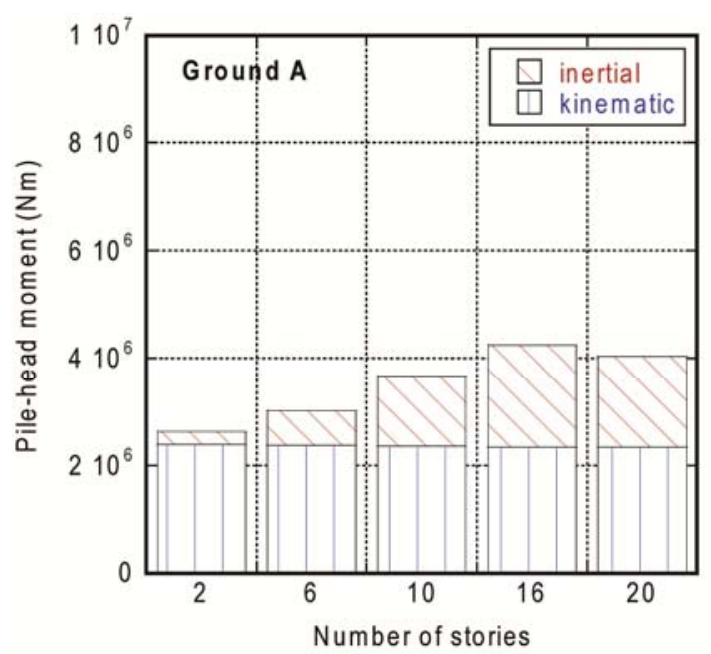

(a) Ground A

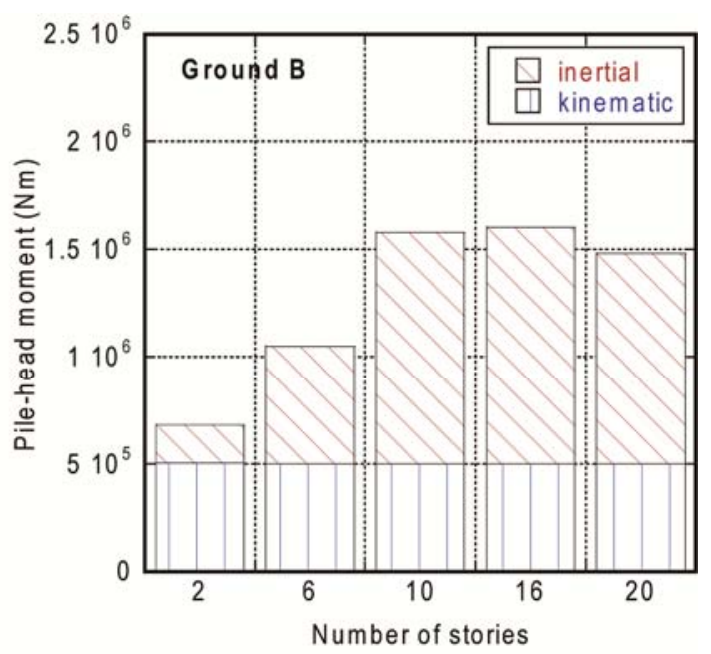

(b) Ground B

Fig.22 Maximum pile-head bending moment due to the kinematic effect and that due to the inertial effect for 2, 5, 10, 16 and 20-story buildings under safety-limit level motion (Ground A and Ground B)

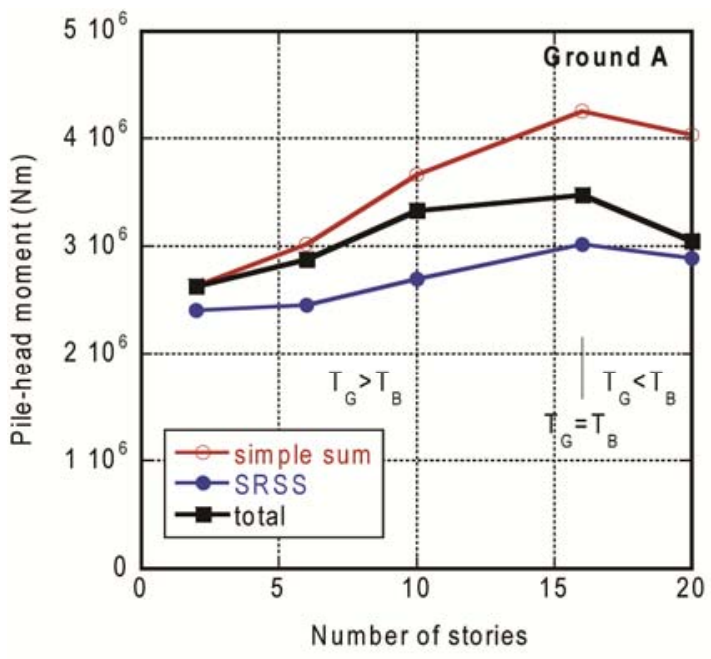

(a) Ground A

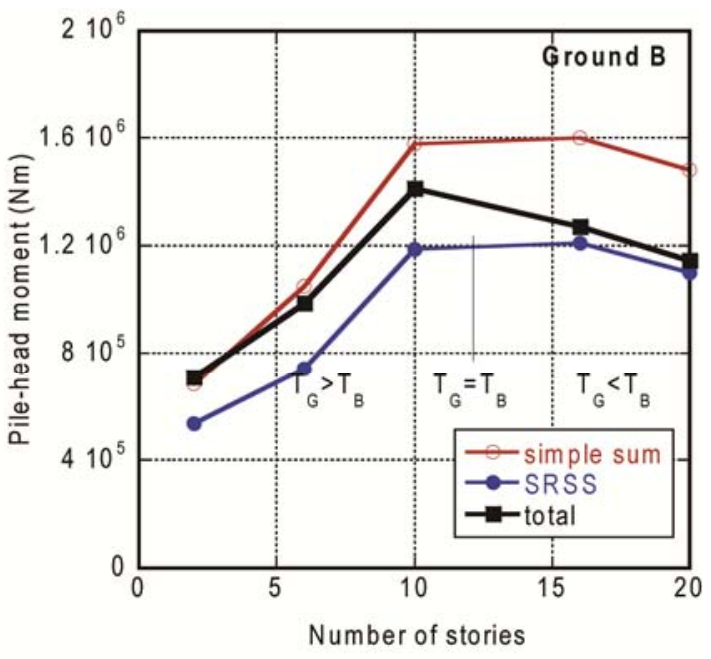

(b) Ground B

Fig.23 Comparison of the maximum pile-head bending moment under safety-limit level motion among (i) simple sum of kinematic and inertial responses, (ii) SRSS of kinematic and inertial responses and (iii) total (true) one 

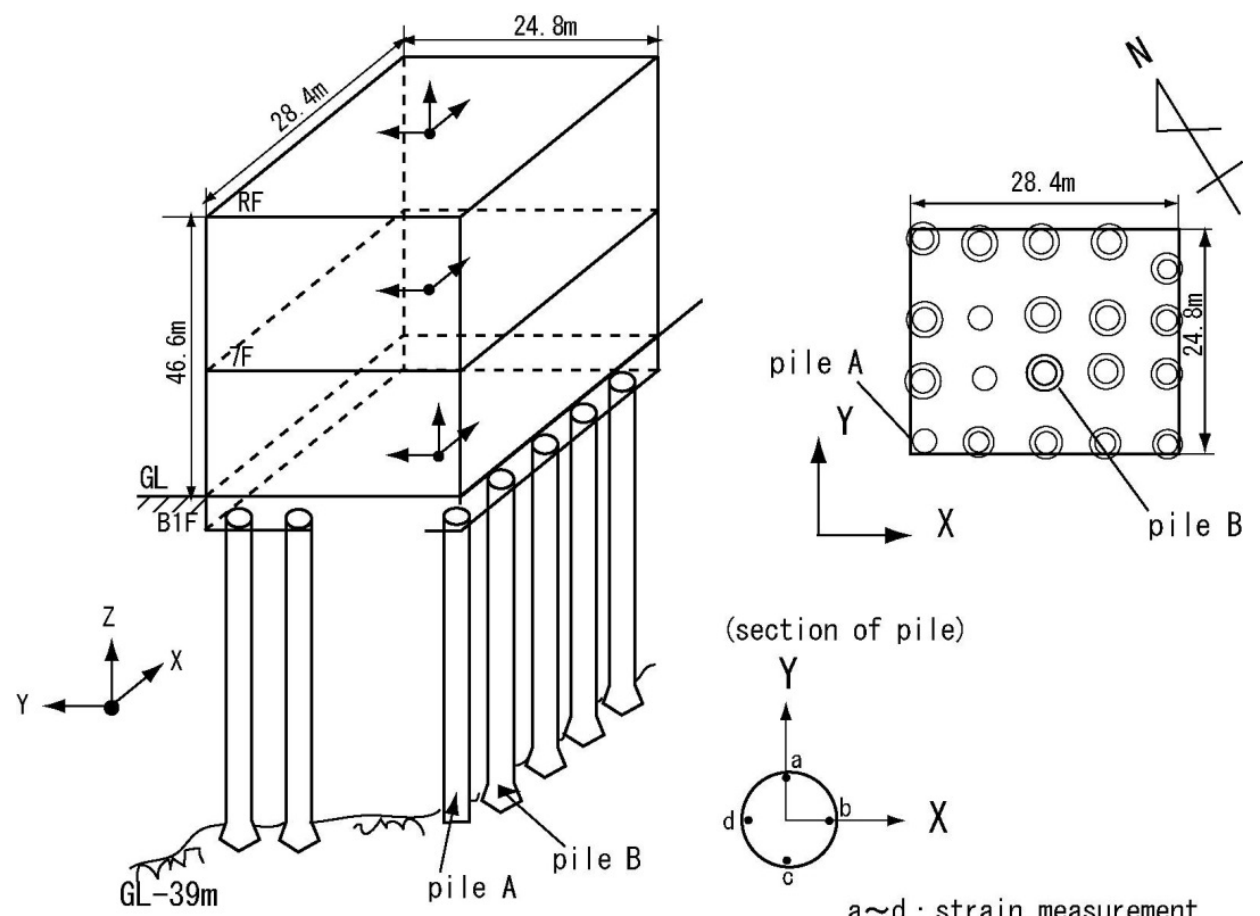

Fig.24 12-story steel building with 20 piles at Yokohama in Japan [23]

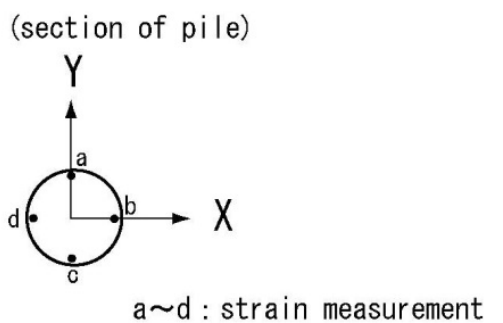

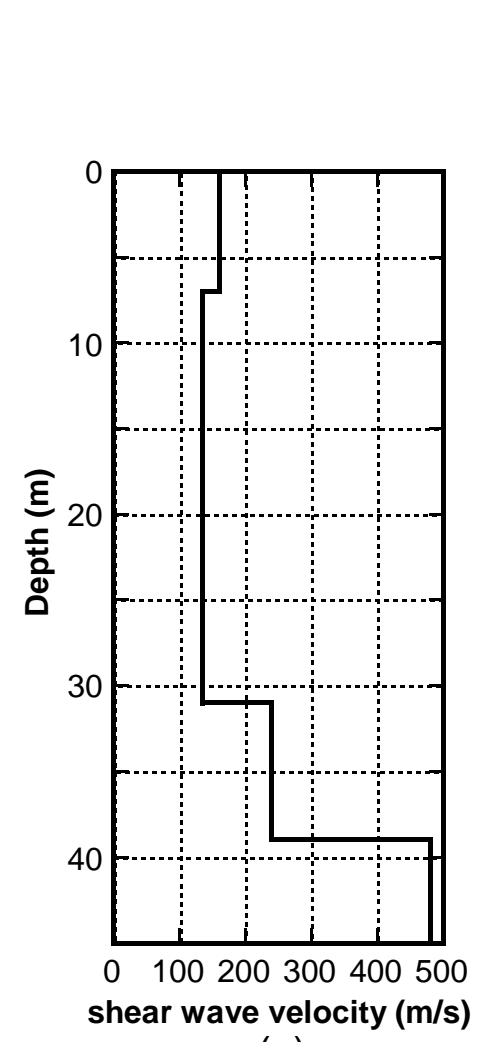

(a)

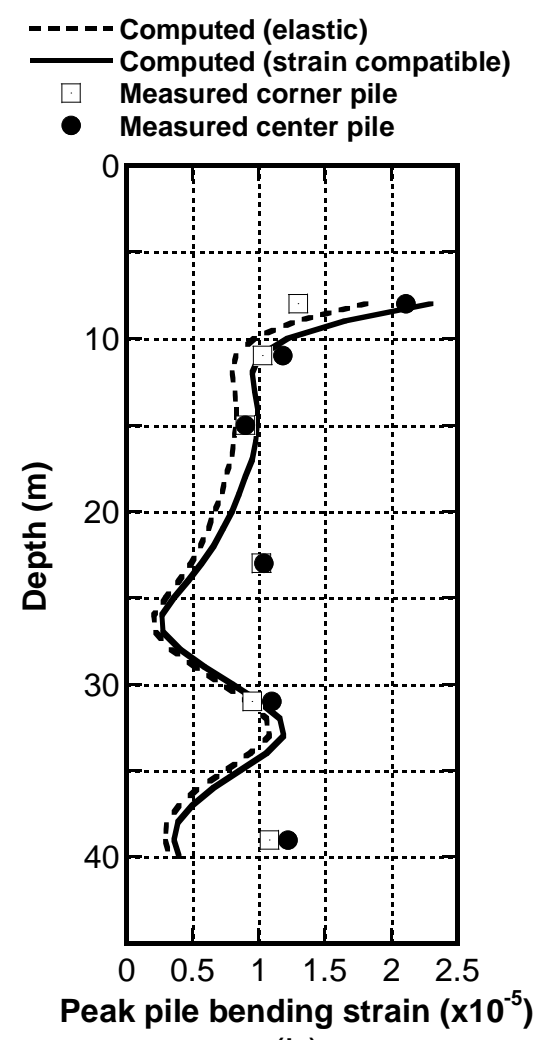

(b)

Fig.25 (a) shear wave velocity profile of the ground, (b) comparison of the peak pile bending strain computed by the analytical model including the present Winkler-type soil element with that recorded during an earthquake in 1992 [23] 


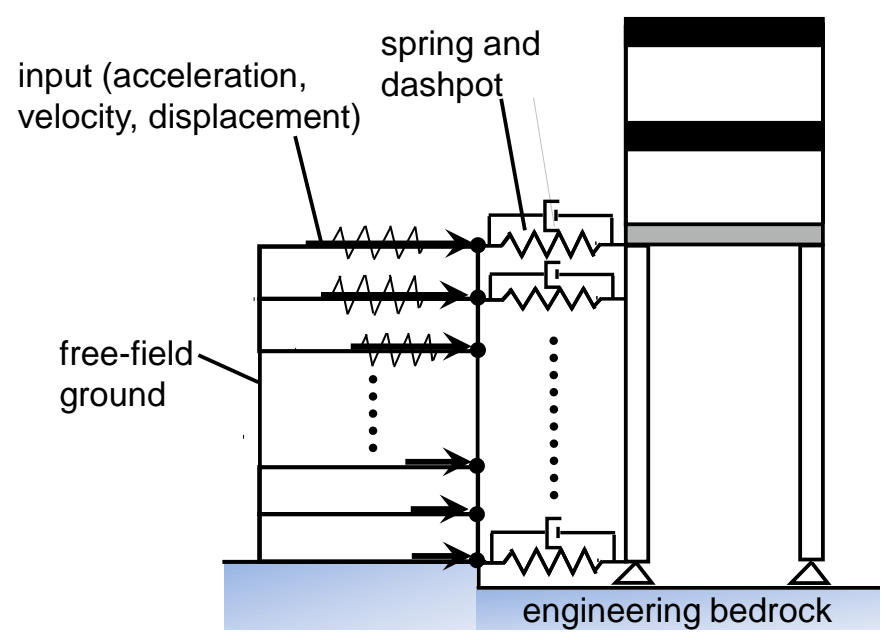

Fig.26 Response analysis model

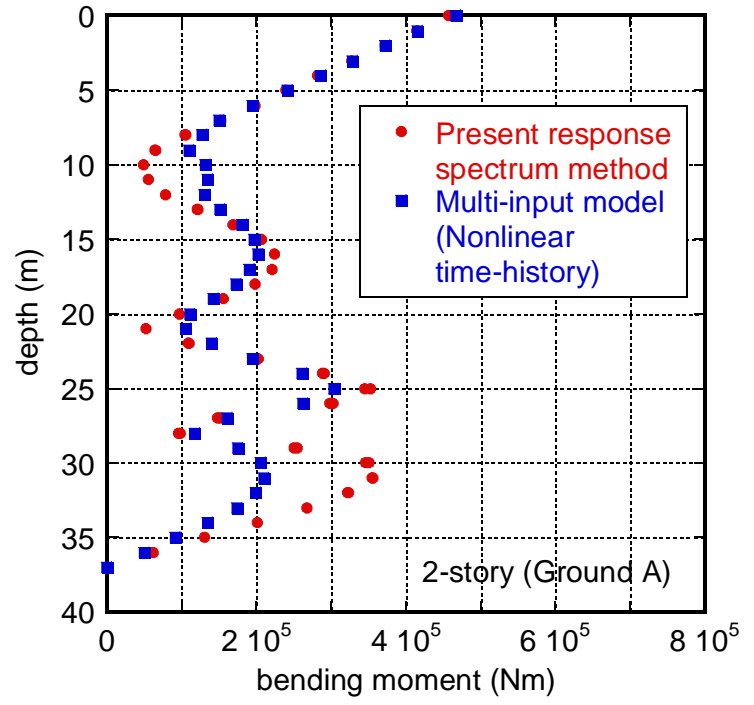

(a)Damage-limit level input

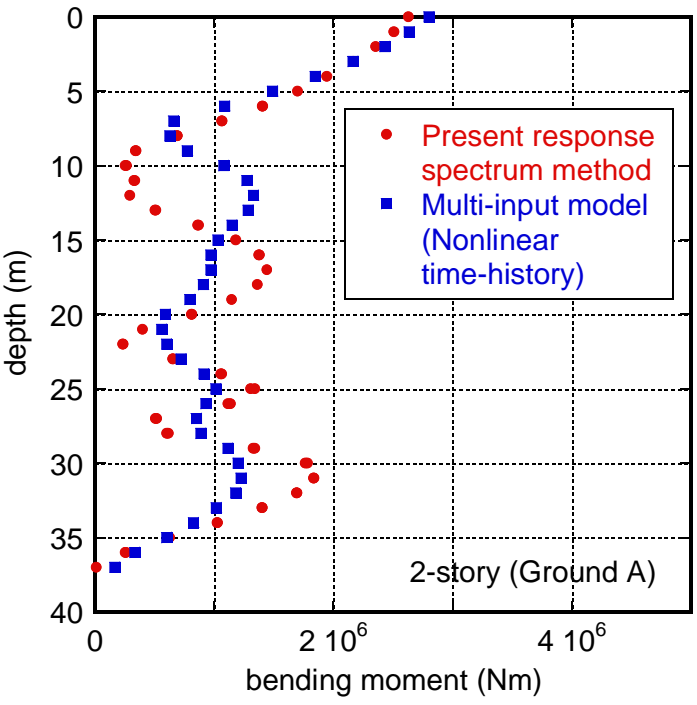

(b)Safety-limit level input

Fig.27 Comparison of pile bending moments between the present response spectrum method and the multi-input model with nonlinearity (Damage-limit level input and Safetylimit level input; Ground A; 2-story building model) 


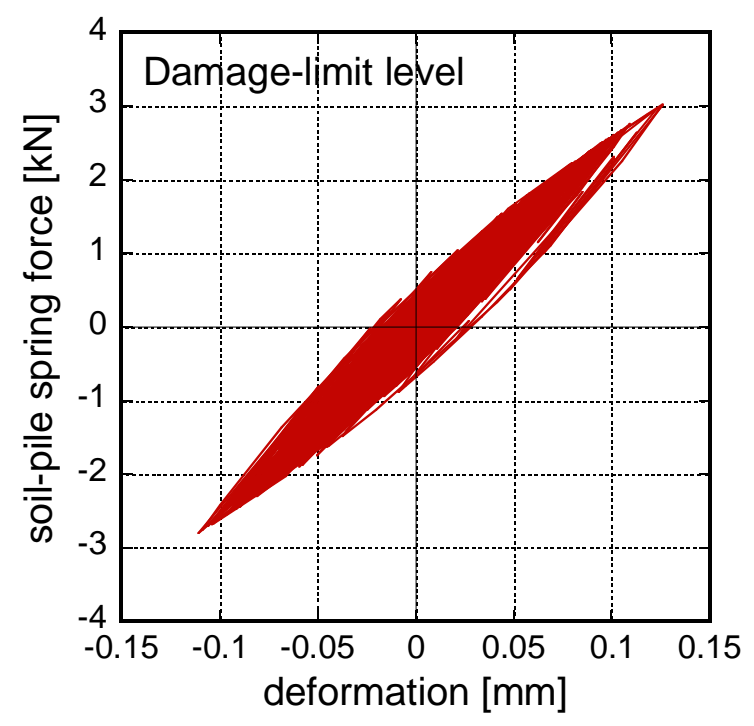

(a)Damage-limit level input

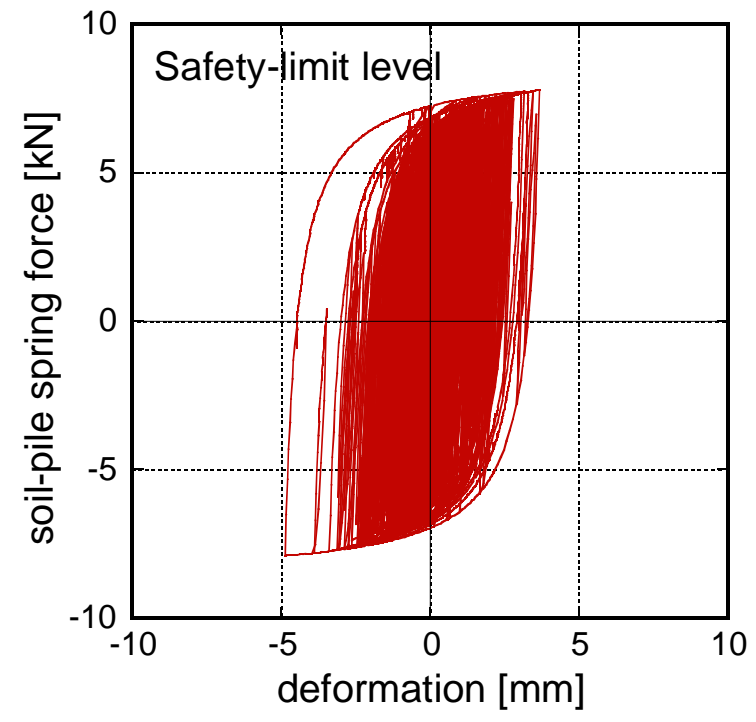

(b)Safety-limit level input

Fig.28 Hysteretic behavior of non-linear soil-pile spring at ground surface level (top spring) with respect to deformation (Damage-limit level input and Safety-limit level input; Ground A; 2-story building model)

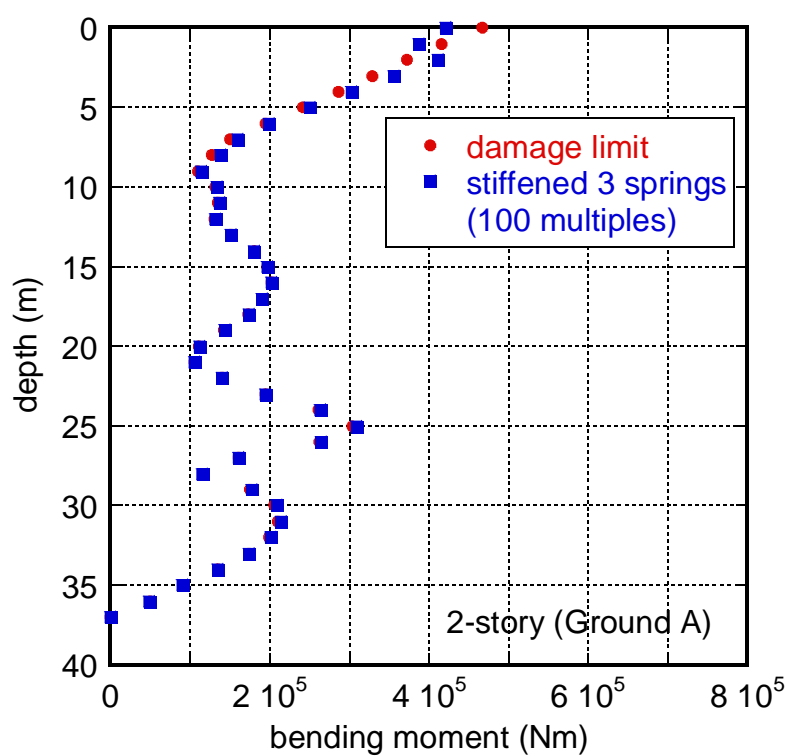

Fig.29 Comparison of maximum pile bending moments under damage-limit level input between original model and modified model, simulating earth pressure acting on embedded foundation, for varied stiffness of three pile-soil springs near ground surface (100 multiples of original value) 


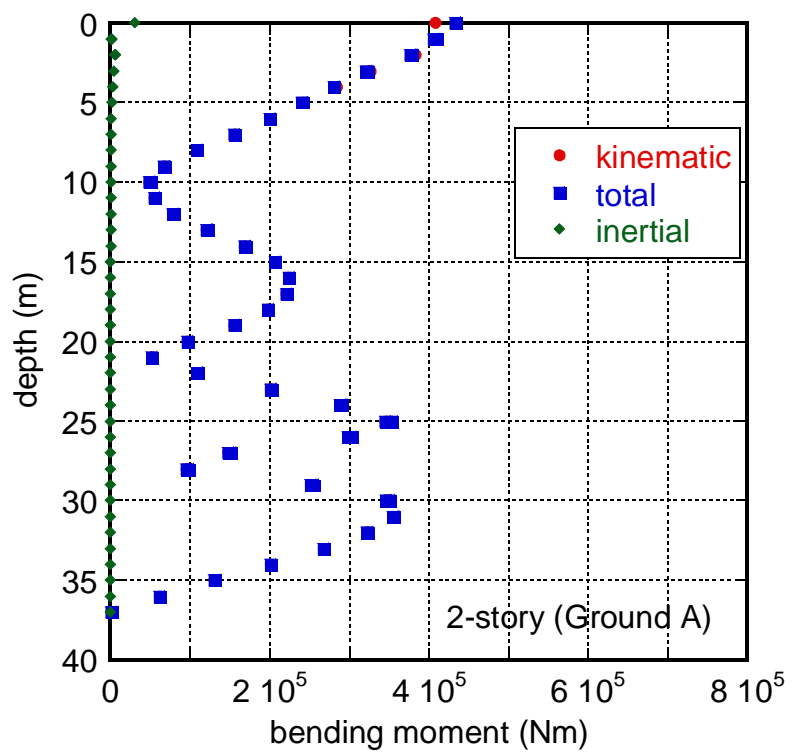

Fig.30 Maximum bending moment distribution of the pile due to the kinematic response, the inertial response and their total response computed by the proposed response spectrum method which corresponds to the topmost one in Fig.12(a) (Ground A; 2-story building model; stiffness of upper two interaction elements has been increased 100 times) 